\title{
Adsorption and photocatalytic degradation of an industrial azo dye using colloidal semiconductor nanocrystals
}

Naim Bel Haj Mohamed ( $\sim$ naimhajmed@gmail.com )

Universite de Kairouan https://orcid.org/0000-0003-2952-4265

\section{Sabri Ouni}

University of Monastir: Universite de Monastir

Mohamed Bouzid

University of Monastir: Universite de Monastir

Mohamed Bouzidi

University of Hail

Adrian Bonilla-Petriciolet

Aguascalientes Institute of Technology: Instituto Tecnologico de Aguascalientes

Mohamed Haouari

University of Monastir: Universite de Monastir

\section{Research Article}

Keywords: Functional organic nanocrystals, Methylene blue, Adsorption, Photocatalysis, Statistical physics modeling, Wastewater treatment.

Posted Date: March 1st, 2022

DOI: https://doi.org/10.21203/rs.3.rs-1057236/v2

License: (9) This work is licensed under a Creative Commons Attribution 4.0 International License.

Read Full License 


\section{Adsorption and photocatalytic degradation of an industrial azo dye using colloidal semiconductor nanocrystals}

Naim Bel Haj Mohamed ${ }^{\mathrm{a} *}$, Sabri Ouni ${ }^{\mathrm{b}}$, Mohamed Bouzid ${ }^{\mathrm{c}}$, Mohamed bouzidid,e, Adrian Bonilla-Petriciolet ${ }^{\mathrm{f}}$, Mohamed Haouari ${ }^{\mathrm{b}}$

${ }^{(a)}$ Laboratory of Spectroscopic Characterization and Optical Materials (LaSCOM), University of Sfax, Faculty of Sciences B.P. 1171, 3000, Sfax-Tunisia

${ }^{(b)}$ Laboratory of Advanced Materials and Interfaces (LIMA), University of Monastir, Faculty of Sciences of Monastir, Monastir-Tunisia

${ }^{(c)}$ Laboratory of Quantum and Statistical Physics, LR18ES18, University of Monastir, Faculty of Sciences of Monastir, Monastir-Tunisia

${ }^{(d)}$ Physics Department, Faculty of Science, University of Ha'il, Saudi Arabia

${ }^{(e)}$ Research unit on hetero-Epitaxies and Applications; University of Monastir, Faculty of Sciences of Monastir, Monastir-Tunisia

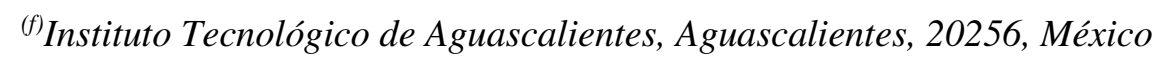

*Corresponding authors: E-mail:naimhajmed@gmail.com

\section{Abstract:}

In this study, mercaptosuccinic acid capped CdSe nanocrystals was successfully synthesized by in-situ medium colloid and used as photocatalyst for the effective photodegradation of methylene blue from aqueous solution under visible light and sunlight irradiations. The particle size and the crystal structure of these nanocrystals were analyzed by different analytical techniques. Dye adsorption prior to photocatalysis using these nanomaterials was studied via the experimental quantification of kinetics and isotherms. These experimental data were modeled including the application of statistical physics theory to analyze the corresponding adsorption mechanism. A maximum adsorption capacity of 27.1 $\mathrm{mg} / \mathrm{g}$ ( $80 \%$ of dye removal) was observed in 10 min using an initial concentration of $30 \mathrm{mg} / \mathrm{L}$. Statistical physics calculations indicated that the adsorption energy was lower than $40 \mathrm{~kJ} / \mathrm{mol}$. It was also established that the dye adsorption was associated to the electrostatic interactions and hydrogen bonding. Overall, the dye removal was a spontaneous, feasible and exothermic 
process. Adsorption properties of CdSe-MSA nanocrystals improved the dye photodegradation efficiency under visible light thus achieving up to $80 \%$ degradation in 60 min. The synergic effect of adsorption and photocatalytic degradation performance was mainly due to the surface area, small size $(3.7 \mathrm{~nm})$ and structural defects (selenium vacancies $\mathrm{S}_{\mathrm{e}}$, interstitial of cadmium $\mathrm{I}_{\mathrm{Cd}}$ ) of nanocrystals, which enhanced the response of these nanomaterials inside the visible range for the photocatalytic activity. In summary, these nanocrystals are promising materials to be used in wastewater treatment under sunlight for the removal of organic compounds like dyes.

Keywords: Functional organic nanocrystals, Methylene blue, Adsorption, Photocatalysis, Statistical physics modeling, Wastewater treatment.

\section{Introduction:}

The increasing consumption of fossil fuels and environmental pollution are major world challenges that require extensive research on different areas including the use of sustainable solar energy (Meinardi et al. 2017; Sauvé and Desrosiers 2014).Various industries (e.g., paper industry, textile industry, cosmetics, paper, clothing and hair coloring) use synthetic organic dyes and, consequently, generate environmental impacts and human health risks upon consumption directly or indirectly. Large-scale production associated to these industries generates polluted effluents that can alter significantly the aquatic environment due to the hazardous toxicological profile of dye molecules (Sousa et al. 2018).On the other hand, the optical and optoelectronic applications such as photocatalysts and solar cells based on semiconductors taking advantage of solar energy have emerged as one of the most promising strategies to resolve energy problems and to meet the fundamental challenge of environmental protection(Belver et al. 2020).

To date, there are several consolidated technologies for wastewater treatment such as adsorption (Azha et al. 2019), membrane-based processes and ultrafiltration (Liu et al. 2017), solvent extraction(Hu et al. 2005), reverse osmosis(Nataraj et al. 2009)and electrochemical treatment. In particular, the advanced oxidation processes (AOPs) are a wide range of technologies applied to degrade the wastewater pollutants based on the generation of reactive oxidant species like hydroxyl $\operatorname{radical}\left({ }^{*} \mathrm{HO}\right)$ or superoxide $\operatorname{radical}\left({ }^{*} \mathrm{O}_{2}{ }^{-}\right)$with high oxidant capacity(Deng and Zhao 2015). During the course of a photocatalytic process, electron-hole pairs are formed in the semiconductor material by irradiation of visible/UV light with energy more than or equal to its bandgap, which can further generate free radicals on the material 
surface. The resulting free radicals are effective oxidizers for the degradation of organic compounds. At the present time, the advanced oxidation processes based on semiconductor photocatalysts have extended their applications including the goal of an effective and ecofriendly wastewater purification(Guo et al. 2013; Jaseela et al. 2019; Bel Haj Mohamed et al. 2021).Photocatalysis is a low-cost and convenient approach to degrade/remove dyes and other organic pollutants from wastewaters by light radiation(Jabeen et al. 2017).During last decades, the nanomaterials have been recognized as excellent catalyst in various fields. The chemical and physical properties of semiconductor nanoparticles can be significantly enhanced in comparison to the bulk counterpart due to their high surface-to-volume ratio; therefore, these nanomaterials have been successfully applied in different branches of science and technology(Peng et al. 2005).Semiconductors in the form of colloidal nanocrystals have a large number of surface atoms and are generally capped with organic ligands, which ensure a surface passivation and prevent their aggregation. Also, these materials are dispersible in solvents allowing their easy processing and they can provide surface functionality adapted to the desired applications. Several studies have been focused on photocatalytic activity for the degradation and removal of different pollutants using distinct semiconductor materials likeTiO ${ }_{2}$ (Hashimoto et al. 2005), $\mathrm{ZnO}$ (Raskar et al. 2019),ZnS(Raskar et al. 2019),CdS(Zhao et al. 2007), $\mathrm{SnO}_{2}$ (Cheng et al. 2018) and GO-based composites (Han et al. 2018).CdSe is a ntype semiconductor with a band gap in the visible range (1.65-1.8 eV) (Lo et al. 2004; Kotkata et al. 2009)and it has received numerous applications in labeling(Wang et al. 2011), sensors(Huang et al. 2008), optometric devices(Jung et al. 2008),solar cells(Yang et al. 2011; Im et al. 2010) and photocatalysis(Lo et al. 2004).Although it has been widely used for biological applications, its immobilization on a solid support for photocatalytic applications has not been explored extensively.

As stated, there are physical, chemical and biological techniques used to remove dyes from an aqueous solution. Nevertheless, these methods may show disadvantages such as energy intensiveness, long processing time, high cost and generation of toxic wastes or subproducts (Sajab et al. 2013).To the best of author knowledge, several researchers have indicated that the adsorption process is considered as one of the most promising technologies to treat dye-containing wastewaters because of its simplicity of design, ease of operation, cost-effective, wide source of adsorbents and it does not produce harmful substances and wastes(Ilgin et al. 2019; Yazidi et al. 2019; Atrous et al. 2019).Inorganic and organic adsorbents have been applied to remove dyes from an aqueous solution. However, some of these adsorbents may suffer from problems in the separation from the treated fluid and their 
performance can be affected by the presence of co-adsorbates in wastewaters. It is important to indicate that the adsorption phenomenon is also present in the photodegradation of organic pollutants from water. It has been demonstrated that the photocatalytic degradation rate depends significantly on the adsorption properties of the photocatalyst for the target pollutant molecules. Note that the adsorption of pollutant molecules on catalyst surface can significantly improve the degradation efficiency. In this regard, the semiconductor nanocrystals can be used as an effective adsorbent due to their good chemical and thermal stability, solubility in a wide range of operating conditions, surface area, morphology, low cost and feasible synthesis method(Bel Haj Mohamed et al. 2014, 2018).Therefore, this paper has focused on the preparation of semiconductor nanocrystals with tailorable surface area and high adsorption properties to be used as model photocatalysts for exploring the adsorptionphotocatalysis synergy in the degradation of organic pollutants. Furthermore, the combination of adsorption and photocatalytic degradation has been analyzed to determine its potential application to treat wastewaters polluted by organic molecules.

Based on this background, the synthesis of CdSe-mercaptosuccinic acid (CdSe-MSA) colloidal nanocrystals and their application in the adsorption/photodegradation of a dye molecule are reported in this paper. Methylene blue (MB) is a cationic thiazine dye that was used as a model dye molecule to evaluate the photocatalytic activity of NCs. The adsorption of MB on CdSe-MSA was performed at different operating conditions to determine kinetics and isotherms where the effect of temperature was analyzed on the adsorptionphotodegradation process. Statistical physics and thermodynamic calculations were carried out to interpret this system. Overall, the kinetics analysis and modeling results indicated that a synergistic effect between adsorption and photocatalysis was present for MB removal with colloidal nanocrystals, which improved the photocatalytic performance. A possible mechanism for the MB degradation was also proposed using these results.

\section{Materials and Methods}

\subsection{Materials}

Analytical grade chemicals were used without further purification. They included cadmium (II) acetate dehydrate (Sigma-Aldrich, $\mathrm{C}_{4} \mathrm{H}_{6} \mathrm{CdO}_{4} 2 \mathrm{H}_{2} \mathrm{O}, \geq 98 \%$ ), selenium dioxide (Sigma-Aldrich, $\mathrm{SeO}_{2}, \geq 98 \%$ ), sodium borohydride (Sigma-Aldrich, NaBH4, 98\%), mercaptosuccinic acid (Sigma-Aldrich, $\left.\mathrm{C}_{4} \mathrm{H}_{6} \mathrm{O}_{4} \mathrm{~S}, 97 \%\right)$ and sodium hydroxide $(\mathrm{NaOH}, 99 \%)$. All aqueous solutions were prepared with ultra-pure water. MB dye $\left(\lambda_{\max }=665 \mathrm{~nm}\right.$, MerckLtd, India) was used as received without further purification(Asfaram et al. 2015; 
Safardoust-Hojaghan and Salavati-Niasari 2017) and its molecular structure is described in Table 1.

\subsection{Preparing of MSA-capped CdSe nanocrystals}

In this work, CdSe nanocrystals were prepared by an aqueous method in the presence of organic capping molecule mercaptosuccinic acid (MSA). The method for the preparation of nanocrystals was based on a previous study of nanocrystals of II-VI semiconductors(Ben Brahim et al. 2017; Ouni et al. 2021).In particular, $\mathrm{Cd}\left(\mathrm{CH}_{3} \mathrm{OO}\right)_{2} \mathrm{H}_{2} \mathrm{O}$ and MSA were mixed in deionized water by stirring in a three-necked flask at room temperature. The solution was then degassed by bubbling nitrogen for $30 \mathrm{~min}$. The $\mathrm{pH}$ of the resulting mixture was adjusted to 11 by dropwise addition of $\mathrm{NaOH}(1 \mathrm{M})$ until the solution became transparent and clear. An aqueous solution of $\mathrm{Na}_{2} \mathrm{SeO}_{3}$ was prepared using selenium dioxide $\left(\mathrm{SeO}_{2}\right), \mathrm{NaOH}$ solution and a quantity of the reductant sodium borohydride $\left(\mathrm{NaBH}_{4}\right)$ to obtain the $\mathrm{Se}^{2-}$ precursor. Then, this solution was quickly injected with a syringe into the flask containing the stock solution and the mixture was heated at $100{ }^{\circ} \mathrm{C}$ under the presence of $\mathrm{N}_{2}$ with continuous refluxing. After $2 \mathrm{~h}$, the color of this solution changed from colorless to yellow. This color change was related to the formation of CdSe-MSA nanocrystals. Finally, as soon as the desired temperature was reached, the flask was cooled to stop the growth of these nanocrystals. The nanocrystals powders precipitated by centrifugation and washed three times with water, ethanol and 2-propanol. Note that the nanocrystals colloidal dispersion was stable, homogeneous and light yellow. They were stored at room temperature until their further use in photocatalytic studies.

\subsection{Photocatalyst characterization}

Several analytical techniques were used to investigate CdSe nanocrystals.XRD measurements were performed using a Philips X'Pert PRO MPD diffractometer equipped with a $\mathrm{CuK} \alpha$ radiation source $(\lambda=1,542 \AA)$. The diffraction patterns were recorded in the range of $2 \theta$ from 20 to $70^{\circ}$ using a step size of 0.02.TEM images were obtained with a JEOL 2010 microscope operated at $200 \mathrm{kV}$. Nanocrystals were dropped on carbon-coated copper grids to obtain TEM samples where the excess solvent was evaporated. The nanocrystals size and size-distribution data were obtained based on the TEM images by measuring at least 100 randomly selected nanocrystals using image processing program (ImageJ, version 1.50). A multichannel Raman spectrometer T64000 Jobin-Yvon-Horiba equipped with an Olympus BX40 confocal microscope system was used to record the Raman spectra. An argon krypton 
laser operated at $488 \mathrm{~nm}$ with approximately $50 \mathrm{~mW}$ of radiation power was used to analyze the sample. FTIR spectra were recorded using a Perkin Elmer (version 5.3) spectrophotometer at room temperature in the spectral range of $400-4000 \mathrm{~cm}^{-1}$ using $\mathrm{KBr}$ pellet disks. The absorption spectra were recorded in the wavelength range of $200-800 \mathrm{~nm}$ at room temperature using a SPECORD 210 Plus spectrophotometer with a quartz cuvette. Photoluminescence (PL) spectroscopy was applied to analyze the defects and emission properties of the CdSe using the exciting source of a $325 \mathrm{~nm}$-line helium-cadmium laser. Photocatalytic experiments were carried out under irradiation using UV light source (Arc Lamp 50-500W, 66901, Newport) and sunlight.

\subsection{Kinetics and isotherms of MB adsorption}

These experiments were used to analyze the impact of temperature and dye concentration on the MB adsorption. For the adsorption kinetic experiments, $30 \mathrm{mg}$ of CdSe nanocrystals powder was added to $30 \mathrm{~mL}$ of $\mathrm{MB}$ aqueous solution at the initial concentrations of 10,15 , 20, 25 and $30 \mathrm{mg} / \mathrm{L}$. All concentrations of dye solutions were prepared by diluting the stock solution $(100 \mathrm{mg} / \mathrm{L})$. The solution $\mathrm{pH}$ was adjusted at 7 and controlled by adding $\mathrm{NaOH}$ into the solution during the experiment. This $\mathrm{pH}$ value was chosen as optimum value for obtaining the maximum adsorption(Kaur et al. 2019).As a result, the efficiency of MB photodegradation was expected to increase with solution $\mathrm{pH}$ due to the electrostatic interactions between the negative photocatalyst surface and MB cations. The adsorption isotherms of MB dye on CdSe nanocrystals were determined at three temperatures from 300 to 320 K.After the corresponding adsorption experiment, the supernatant fraction was used to determine the adsorption capacities via the quantification of dye concentration with UV-Vis spectroscopy recording the $\mathrm{MB}$ characteristic absorption band at $665 \mathrm{~nm}$. The equilibrium $\mathrm{MB}$ adsorption capacity $\left(\mathrm{Q}_{\mathrm{e}}\right)$ was calculated with the following equation (R. et al. 2018; Li et al. 2020)

$$
\mathrm{Q}_{\mathrm{e}}(\mathrm{mg} / \mathrm{g})=\frac{\mathrm{V}\left(\mathrm{C}_{0}-\mathrm{C}_{\mathrm{e}}\right)}{\mathrm{m}}
$$

while the dye removal (\%) of nanocrystals was obtained via the next equation:

$$
\text { Dye removal }=\frac{\left(\mathrm{C}_{0}-\mathrm{C}_{\mathrm{t}}\right)}{\mathrm{C}_{0}} \times 100
$$

where $C_{0}(m g / L)$ is the initial concentration, $C_{e}(m g / L)$ is the equilibrium concentration in the solution, $C_{t}(\mathrm{mg} / \mathrm{L})$ is the dye concentration at time $t, V$ is the volume of the solution $(L)$ and $m$ 
is the mass of the CdSe-MSA catalyst $(g)$. Each adsorption experiment was performed for $2 \mathrm{~h}$ with magnetic stirring in the dark.

\subsection{Photocatalytic degradation of MB}

A comparative study of the photocatalytic degradation of MB dye in aqueous solution was performed using two types of irradiation: a mercury lamp and sunlight. For this photocatalytic process, $30 \mathrm{mg}$ of CdSe-MSA nanocrystals were mixed with a $30 \mathrm{~mL}$ of a MB solution with initial concentration of $10 \mathrm{mg} / \mathrm{Lin} 100 \mathrm{~mL}$ cylindrical Pyrex reactor under continuous stirring. First, the suspension was magnetically stirred in absence of light exposure to reach the adsorption-desorption equilibrium between MB dye and photocatalyst surface. After that, the photocatalysis reaction was started when the suspension was exposed to sunlight or visible light. In successive sampling times, $2 \mathrm{~mL}$ of the solution were taken and precipitated by absolute ethanol to separate the supernatant (dye solution) from the catalyst where the final concentration was determined by UV-Visible spectroscopy. According to the Beer-Lambert law, the degradation efficiency $(\% \mathrm{D})$ of $\mathrm{MB}$ was calculated with the next equation(Kaur et al. 2019):

$$
\% D=\frac{C_{0}-C}{C_{0}} \times 100=\frac{A_{0}-A}{A_{0}} \times 100
$$

where $A, A_{0}, C_{0}$ and $C$ were the absorbance and concentration of MB dye solution $(\mathrm{mg} / \mathrm{L})$ before and after irradiation, respectively, at different times using CdSe-MSA nanocrystals. The photocatalytic degradation of MB with this catalyst followed a pseudo first-order kinetics model, also known as Langmuir-Hinshelwood equation.This model is given by(Ouni et al. 2021; Lakshmipathy et al. 2017):

$$
-\frac{\mathrm{dC}}{\mathrm{dt}}=k_{a p p} \mathrm{C}
$$

Integrating the last equation and using the boundary condition of $\mathrm{C}=C_{0}$ at $t=0$, the next expression is obtained:

$$
\mathrm{C}=C_{0} \mathrm{e}^{-k_{a p p} \mathrm{t}} \leftrightarrow \operatorname{Ln} \frac{\mathrm{C}}{C_{0}}=-k_{a p p} t
$$

Where $k_{a p p}\left(\mathrm{~min}^{-1}\right)$ is the apparent reaction rate constant and $t$ is the irradiation time. Note that $k_{\text {app }}$ was calculated from the slope of $\operatorname{Ln}\left(\mathrm{C} / \mathrm{C}_{0}\right)$ versus $t$. 


\section{Results and discussion}

\subsection{Photocatalyst characterization}

XRD pattern of CdSe-MSA is shown in Figure 1.a and was compared to that of the JCPDS card No. 019-0191.The diffraction peaks were very broad thus indicating a very small crystal size. The high-intensity diffraction peaks at $2 \theta^{\circ}=28.33,44.41$ and $51.34^{\circ}$ matched with the (111), (220) and (311) crystalline planes of the cubic phase of CdSe-MSA. However, it is convenient to note that the high intensity of the (111) peak suggested that this direction was the most preferred. A shift in the peak positions corresponding to the nanocrystals sample compared to those of the CdSe bulk crystal was identified according to the JCPDS data cards. This shift was originated from the relaxation at the surface often observed in crystals of very low dimension, which altered the inter-plan distances that became small(Wang et al. 2017).From the (111) plane, the crystallite size of the nanocrystals was calculated to be $1.7 \pm$ $0.1 \mathrm{~nm}$ using the Debye Scherrer formula:

$$
\mathrm{D}=\frac{0.9 \lambda}{\beta_{\mathrm{hkl}} \cos \theta}
$$

where $\mathrm{D}$ is the average crystal size in $\mathrm{nm}, \mathrm{K}=0.9$ is the shape factor, $\lambda=0.15406 \mathrm{~nm}$ is the wavelength of $\mathrm{X}$-ray, $\beta_{\mathrm{hkl}}$ is the full width at half maximum and $\theta$ is the reflection angle of Bragg. For the cubic crystal structure of CdSe, the lattice parameter was calculated from the (111) plane and was $5.74 \AA$, which was considerably lower than its corresponding bulk value $(6.05 \AA)$.Note that Scherrer's formula only takes into account the effects of the crystallite size that come from the XRD peak broadening, but the possible presence of intrinsic strain within the crystal (i.e., grain boundary, stacking faults, dislocations) are not considered. Therefore, it then provided an overestimation of the nanocrystals size for the compressive strain and under estimation for the size for the extensive strain(Nath et al. 2020).Therefore, the method proposed by Williamson and Hall allowed deconvoluting the two effects: size and microstrain(Nath et al. 2020; Williamson and Hall 1953). This method considers that all the peaks are purely Lorentzian. Indeed, the integral width $\beta_{\text {total }}$ of the convolution of a Gaussian of the nanocrystals is the integral width $\beta_{\text {size }}$ due to the size effect and the integral width $\beta_{\text {strain }}$ due to micro-stress from the physical line broadening of X-ray diffraction peak:

$$
\beta_{h k l}=\beta_{\text {size }}+\beta_{\text {strain }}
$$

The micro-strain $\varepsilon$ and broadening $\beta_{\text {strain }}$ are related by the following relation(Stokes and Wilson 1944): 
251 So, the total broadening due to strain and size, in a particular peak having the $h k l$ value, can 252 be expressed as:

$$
\beta_{h k l}=\frac{0.9 \lambda}{\mathrm{D} \cos \theta}+4 \varepsilon \tan \theta
$$

The last equation can be re-arranged to get:

$$
\beta_{h k l} \cos \theta=\frac{0.9 \lambda}{\mathrm{D}}+4 \varepsilon \sin \theta
$$

Plotting the value of $\beta_{\mathrm{hkl}} \cos \theta$ as a function of $4 \sin \theta$ (see Figure 1.b) can be used to estimate the micro-strain where $\varepsilon$ can be estimated from the line slope and the crystallite size from the intersection with the vertical axis. This linear regression showed a determination coefficient $\mathrm{R}^{2}=0.99$.Therefore, the intrinsic strain and particle size were 0.166 and $0.41 \mathrm{~nm}$, respectively. This compressive strain was a consequence of the reduced lattice parameter of the crystals. This result confirmed that the compressive strain of surface generated by organic ligands, during the growth of CdSe-MSA nanocrystals, resulting in the crystallinity imperfection and distortion through the relaxation of atomic positions( $\mathrm{Wu}$ et al. 2007; Thandavan et al. 2015).High Resolution Transmission Electron Microscopy (HRTEM) images of $\mathrm{CdSe}$ nanocrystals are shown in Figure 2.a.These images demonstrated the formation of monodisperse nanocrystals with reasonable spherical shape.The histogram of nanocrystals size distribution indicated a mean value of $3.7 \pm 0.1 \mathrm{~nm}$, see Figure 2.b, which was nearly the same value as that obtained from XRD data analysis. The clear continuous lattice fringes obtained by HRTEM images were associated to the single-crystalline property of CdSe-MSA. The observed interplanar spacing of $0.34-0.37 \mathrm{~nm}$ corresponded to the (111) crystalline planes of cubic phase thus showing that the nanocrystals grown along (111) plane. FTIR spectroscopy was used to identify the surface modification of CdSe nanocrystals by grafting an organic ligand with the thiol group $(\mathrm{S}-\mathrm{H})$ to allow their binding to cadmium. A typical FT-IR spectrum is shown in Figure 3.The total disappearance of the characteristic band of the thiol group (S-H), which is generally observed between $2560-2660 \mathrm{~cm}^{-1}$, indicated the cleavage of the $\mathrm{S}-\mathrm{H}$ bond and the fixation of the sulfur atom and cadmium atoms on the nanocrystals surface (Bel Haj Mohamed et al. 2021; Arivarasan et al. 2019; Abd El-sadek and Babu 2011). Furthermore, MSA capped CdSe nanocrystals showed a broad absorption bands at around $3280 \mathrm{~cm}^{-1}$ due to the presence of $\mathrm{OH}$ stretching vibration of water molecules. The band located at $2982 \mathrm{~cm}^{-1}$ corresponded to the vibration mode by asymmetric stretching bond 
of $-\mathrm{CH}_{2}$. The $\mathrm{C}=\mathrm{O}$ vibrational band of MSA molecules at $1697 \mathrm{~cm}^{-1}$ was shifted to a lower frequency at about $1560 \mathrm{~cm}^{-1}$. The bands located at $1380 \mathrm{~cm}^{-1}$ corresponded to symmetric vibration of the (COO-) group. The band at $918 \mathrm{~cm}^{-1}$ could is caused by $\mathrm{C}-\mathrm{H}$ bending. These results clearly indicated that the MSA molecules were well attached to the surface of CdSe nanocrystals.

Raman spectroscopy was employed to investigate the resonances and to estimate if they were due to the size, lattice parameter or surface strain of the CdSe nanocrystals. Also, the magnitude order of these modes of lattice vibrations was determined and the crystalline quality of synthesized nanocrystals was evaluated. Figure 4 shows the Raman spectrum of CdSe-MSA nanocrystals. Raman spectrum contained two principal peaks at 194.3 and 295.7 $\mathrm{cm}^{-1}$. The first was attributed to the first order of longitudinal optical(1LO)phonons of CdSe with a low wavenumber shift of $17 \mathrm{~cm}^{-1}$ compared to the $1 \mathrm{LO}$ mode of bulk $\mathrm{CdSe}$ ( $\mathrm{LO} \mathrm{CdSe}=$ $212 \mathrm{~cm}^{-1}$ ) (Todescato et al. 2013; Neto et al. 2010). This shift was due to the reduction in size of the CdSe nanocrystals. At the same time, the 1LO peak of CdSe had a low intensity band between 150-180 $\mathrm{cm}^{-1}$ corresponding to the surface optical (SO) phonons due to the large specific surface area and LO phonons of the CdSeS alloy at the interface of nanocrystalsligand(Chaparro et al. 2000; Tschirner et al. 2012).

In terms of intensity, this $1 \mathrm{LO}$ phonon band of CdSe was weaker. This finding was related to the less ordered in the nanocrystals structure. This behavior was observed with the broader band in the (111) plane in the XRD analysis and the compressive strain calculated by the Williamson-Hall method.The second band was also associated with the longitudinal optical (1LO) phonons of CdSeS alloy and CdS nanocrystals, which was in agreement with those measured experimentally(Tschirner et al. 2012).The absence of impurity and defect-related vibrational modes suggested the occurrence of only a single phase of the synthesized nanocrystals. This result showed that ligand coating had occurred on the CdSe nanocrystals involving the sulfur atom of the ligand with $\mathrm{Cd}$ atoms at their surface.

$\mathrm{UV}-\mathrm{V}$ is spectra were recorded to determine the size, absorption range and band gap energy, as presented in Figure 5.a.CdSe-MSA nanocrystals had a large absorption starting from 580 $\mathrm{nm}$, which became strong near $380 \mathrm{~nm}$ thus indicating that MSA capped CdSe nanocrystals can absorb a significant portion of visible light. Band gap energy $E g$ values for these nanocrystals can be estimated from the UV-vis spectrum using the Tauc model (Soltani et al. 2013) : 


$$
\alpha h v=A\left(h v-E_{g}\right)^{1 / 2}
$$

Where $\alpha$ is the absorption coefficient, $\hbar v$ is the photon energy, $\mathrm{A}$ is a constant and $n=1 / 2$ is a transition-dependent factor.The absorption coefficient $(\alpha)$ was determined from BeerLambert's relation(Soltani et al. 2013, p.):

$$
\mathrm{A}=\frac{\mathrm{I}}{\mathrm{I}_{0}}=\mathrm{e}^{(-\alpha \mathrm{d})} \text { or } \alpha=2.303 \frac{\mathrm{A}}{\mathrm{d}}
$$

Where $d$ is the path length of the quartz cuvette and $\mathrm{A}$ is the absorbance determined from the UV-Visible spectrum. The band gap energy values can be determined by extrapolation of the linear part of $(\alpha h v)^{2}$ versus $h v$, see Figure 5.b.The line intersection with the $\mathrm{x}$-axis corresponded to the value of the optical gap energy. The estimated band-gap energy of CdSeMSA nanocrystals increased from 1.74 to $2.4 \mathrm{eV}$, which was due to the quantum confinement effects induced by the nanosized crystallites in CdSe semiconductors, subsequent in more discrete energy spectra(Smida et al. 2018). This result indicated that the CdSe-MSA had a suitable band gap for photocatalytic decomposition of organic contaminants under visiblelight irradiation.

The exciton peak position can be converted into the corresponding particle size of nanocrystals using the next empirical expressions(Bacherikov et al. 2006):

$$
D=0.344 \exp \left(\frac{\lambda_{\max }-252.7}{129.3}\right)
$$

In the case of these nanocrystals, $\lambda_{\max }$ was $480 \mathrm{~nm}$ and the corresponding $\mathrm{D}$ value was $2 \mathrm{~nm}$, which was slightly greater than the sizes obtained from XRD and TEM results. CdSe nanocrystals have $\lambda>400 \mathrm{~nm}$ indicating that they were suitable for the solar spectrum. Therefore, there was an enhancement in photocatalytic efficiency under solar light because the samples were capable to absorb more amount of solar energy for the degradation of organic molecules like dyes(Dake et al. 2020).

The PL spectrum of purified CdSe-MSA nanocrystals was obtained using a photoluminescence spectrophotometer with an excitation wavelength $\lambda_{\text {exc }}=325 \mathrm{~nm}$ at room temperature. Figure 6 shows PL spectrum of CdSe nanocrystals redispersed in water.PL spectrum showed a broad emission band around 532nm with a FWHM of 126nm. Since the absorption maximum was located at approximately 391nm, a Stokes shift of approximately $141 \mathrm{~nm}$ was identified between the absorption threshold and the emission maximum at $532 \mathrm{~nm}$ (Figure 5.a). Due to the large surface-to-volume ratio of the nanoparticles size and incomplete 
surface passivation, these surface atoms can represent some localizing defect sites owing to unsaturated dangling bonds, which behaved as carrier trapping sites thus resulting in nonradiative recombination and leaded to a large emission spectrum shift with a FWHM increase. Moreover, this shift resulted from the global response of the nanocrystals sizes distribution because the transition energies collected on these populations were integrating all the transition energies of all the nanocrystals.

A Gaussian fitting allowed to decompose the emission spectrum into 3 intense and broad bands in the visible range located at $458 \mathrm{~nm}(2.71 \mathrm{eV}), 525 \mathrm{~nm}(2.32 \mathrm{eV})$ and $592 \mathrm{~nm}(2.09$ $\mathrm{eV})$.The first blue emission located at $458 \mathrm{~nm}$ was strongly correlated to the nanocrystals size and was attributed to the direct recombination of excitons between the band edges (the fundamental exciton recombination). It was attributed to radiative recombination of an electron from the conduction band (BC) to the valence band or from the conduction band with a thiol group energy level $\left(\mathrm{R}-\mathrm{S}^{-}\right)$from organic ligands localized on the surface of $\mathrm{CdSe}$ nanocrystals(Bel Haj Mohamed et al. 2021; Soheyli et al. 2017).The presence of MSA can also provide carrier (hole) trapping sites and leads to quenching of radiative excitonic recombination. As suggested by Klimov et al.(Klimov et al. 1999), the hole trapping sites were not related defects, but rather arisen from intrinsic nanocrystal states or surface states that remained unchanged even after surface treatment(Klimov et al. 1999).Due to surface states of $\mathrm{Cd}^{2+}$ or $\mathrm{Se}^{2-}$ ions, it twisted energy states within the band gap in the nanocrystals. The band located at $525 \mathrm{~nm}$ may be due to the contribution of an electron localized on a selenium vacancy $\left(\mathrm{V}_{\mathrm{Se}}\right)$ with a hole in the valence band (BV)(Klimov et al. 1999). Note that the last band located at $592 \mathrm{~nm}$ was attributed to the transition from cadmium interstitial of $\left(\mathrm{I}_{\mathrm{Cd}}\right)$ to the valence band (BV)(Bel Haj Mohamed et al. 2021; Gaponenko 1998).Finally, the large emission could be accredited to the selenium vacancy and interstitial of cadmium generated in the CdSe nanocrystals, which played a vital role in the photocatalytic activity.

\subsection{Adsorption and photocatalytic degradation of MB dye}

\subsubsection{Adsorption kinetics}

Kinetics studies on the MB adsorption were conducted at $28{ }^{\circ} \mathrm{C}$. Figure 7 shows the pseudofirst-order and pseudo-second-order kinetic models used to correlate the MB adsorption on CdSe-MSA nanocrystals. Note that the pseudo-first-order kinetic model has been widely used to predict the dye adsorption kinetics, which is given by(S 1898; Ho and McKay 1999; Pan et al. 2010; Ghasemi et al. 2014): 


$$
q(t)=q_{e}\left(1-\exp \left(K_{1} t\right)\right)
$$

377 Where $q(t)$ and $q_{e}$ represent the amount of dye adsorbed $(\mathrm{mg} / \mathrm{g})$ at any time $t(\mathrm{~min})$ and equilibrium, respectively, and $K_{1}$ is the corresponding adsorption rate constant $\left(\mathrm{min}^{-1}\right)$. The pseudo-second-order kinetic rate equation [2-4] is defined as:

$$
q(t)=\frac{q_{e}^{2} K_{2} t}{1+q_{e} K_{2} t}
$$

381

382

383

Where $K_{2}(\mathrm{mg} / \mathrm{g} \cdot \mathrm{min})$ is the pseudo-second-order rate adsorption constant. Results of adsorption kinetic modeling are reported in Tables 2 and 3.The pseudo-first-order model showed higher $\mathrm{R}^{2}$ than the pseudo-second-order model thus concluding that this model was the best to correlate the MB adsorption kinetics using CdSe-MSA nanocrystals. The adsorption rate constant $K_{1}$ increased as a function of initial MB concentration thus suggesting that the adsorption relaxation time $\left(\tau=1 / K_{1}\right)$ was of the order of a few minutes. Also, it was identified that there were two phases of the adsorption process. The first phase was associated to the diffusion of dye molecules on the nanocrystals surface, while the second one corresponded to the adsorption equilibrium. The adsorption capacity and the adsorption relaxation time varied from 8.87 to $23.9 \mathrm{mg} / \mathrm{g}$ and from 8.13 to $0.107 \mathrm{~min}$, respectively, when the MB concentration increased from 10 to $30 \mathrm{mg} / \mathrm{L}$. These results were related to a high number of adsorption sites available on the nanocrystals surface, which allowed a fast and high mass transfer gradient for the MB diffusion to CdSe-MSA surface. The amount of adsorbed dye increased with the stirring time to reach a plateau after 10 minutes thus indicating the adsorption equilibrium, which was caused by a limited number of $\mathrm{MB}$ molecules that diffused to the CdSe-MSA surface sites. Note that more than $90 \%$ of the maximum catalyst adsorption capacity was reached after $10 \mathrm{~min}$ of stirring. Then, the remaining $10 \%$ was reached after $120 \mathrm{~min}$. Therefore, $120 \mathrm{~min}$ of stirring were required before proceeding with the photocatalytic activity.

\subsubsection{Adsorption isotherms}

Figure 8 and Table 4 show the results of dye adsorption isotherm where the Langmuir, Freundlich isotherm, Langmuir-Freundlich and Redlich-Peterson equations were used to correlate these equilibrium experimental data. In particular, the Langmuir model assumes that the adsorption occurs with the monolayer formation of adsorbate molecules on a 
homogeneous adsorbent surface with uniform energies of adsorption(Langmuir 1918).This model is represented by the following equation(Takeda et al. 1995; Nayak et al. 2017):

$$
q_{e}=q_{\max } \frac{K_{e} C_{e}}{1+K_{e} C_{e}}
$$

Where $C e(\mathrm{mg} / \mathrm{L})$ is the dye concentration in solution at adsorption equilibrium, $q_{e}$ is the equilibrium adsorption capacity $(\mathrm{mg} / \mathrm{mg}), K_{e} \quad(\mathrm{~L} / \mathrm{mg})$ is the equilibrium constant and $q_{\max }(\mathrm{mg} / \mathrm{g})$ is the monolayer adsorption capacity of tested nanocatalyst. The calculated values of the Langmuir parameters were $q_{\max }=31.1 \mathrm{mg} / \mathrm{g}$ and $K_{e}=0.386 \mathrm{~L} / \mathrm{mg}$ with $\mathrm{R}^{2}=$ 0.96. $K_{e}$ value indicated a significant affinity of the adsorbent for the favorable adsorption of MB dye molecules.

On the other hand, the Freundlich model assumes a heterogeneous adsorption surface having sites with different adsorption energies. It is described as(Freundlich 1907):

$$
q_{e}=k_{f} C_{e}^{1 / n_{F}}
$$

Where $K_{f}(\mathrm{mg} / \mathrm{g})$ is the Freundlich adsorption constant and $n_{F}$ is the degree of nonlinearity between solution concentration and adsorption where $1 / n_{F} \in(0.1,1)$ indicates a favorable adsorption. The calculated value of $1 / n_{F}$ was $\sim 0.33$ hthus confirming the favorable $\mathrm{MB}$ adsorption by CdSe-MSA nanocrystals.

Redlich-Peterson is expressed by the following equation(Redlich and Peterson 1959):

$$
q_{e}=\frac{K_{R} C_{e}}{1+a_{R} C_{e}^{\beta}}
$$

where $\mathrm{K}_{\mathrm{R}}(\mathrm{L} / \mathrm{g}), \mathrm{a}_{\mathrm{R}}\left(\mathrm{L} / \mathrm{mg}^{1-1 / \beta}\right)$ and $\beta$ are the corresponding isotherm parameters. Note that if $\beta \rightarrow 1$ the adsorption follows the Langmuir model and if $\beta \rightarrow 0$ the adsorption fits the Freundlich model. Data fitting indicated that $\mathrm{R}^{2}=0.97$ and $\beta=1$ for the Redlich-Peterson isotherm thus confirming the best correlation with a Langmuir-type isotherm model.

Finally, the Langmuir-Freundlich $(L-F)$ isotherm model was also used to describe the adsorption equilibrium data(Abu-Alsoud et al. 2020):

$$
q_{e}=\frac{q_{\max }\left(K_{L F} C_{e}\right)^{n_{L F}}}{1+\left(K_{L F} C_{e}\right)^{n_{L F}}}
$$

where $\mathrm{K}_{\mathrm{LF}}$ is the adsorption affinity constant and $\mathrm{n}_{\mathrm{LF}}$ is the heterogeneity index.

The calculated L-F parameters were $Q_{\max }=27.07 \mathrm{mg} / \mathrm{g}$ and $K_{L F}=0.47 \mathrm{~L} / \mathrm{mg}$ with $\mathrm{R}^{2}=0.98$. Data fitting using this isotherm out performed the results from Langmuir, Freundlich and 
451

Redlich-Peterson models. The maximum adsorption capacity calculated with the LangmuirFreundlich model was $27.1 \mathrm{mg} / \mathrm{g}$, which agreed with the experimental data of $28.5 \mathrm{mg} / \mathrm{g}$.

\subsubsection{Statistical physics modeling}

Statistical physics models were used to complement the analysis of MB adsorption via the calculation of the next physicochemical parameters: the number of adsorbed dye molecules per adsorption site $(n)$, the density of adsorption sites $\left(D_{M}\right)$ and the corresponding adsorption energies. In particular, the Hill model was used assuming that the adsorption was a monolayer process where the adsorption sites of CdSe-MSA nanocrystals can bind a fraction, one or more dye molecules(Bouzid et al. 2016). Also, other statistical physics models were considered assuming that the MB dye molecules were adsorbed via the formation of two layers with one and two different adsorption energies(Bouzid et al. 2016). The mathematical equations of these models are given below(Bouzid et al. 2016; Mohamed et al. 2018; Bouzid et al. 2016; Pang et al. 2020):

Monolayer process:

$$
Q_{e}=\frac{n \cdot D_{M}}{1+\left(\frac{C_{1 / 2}}{C_{e}}\right)^{n}}
$$

Double layer process with one adsorption energy:

$$
Q_{e}=n \cdot D_{M} \frac{\left(\frac{C_{e}}{C_{1}}\right)^{n}+2\left(\frac{C_{e}}{C_{1}}\right)^{2 n}}{1+\left(\frac{C_{e}}{C_{1}}\right)^{n}+\left(\frac{C_{e}}{C_{1}}\right)^{2 n}}(21)
$$

Double layer process with two adsorption energies:

$$
Q_{e}=n \cdot D_{M} \frac{\left(\frac{C_{e}}{C_{1}}\right)^{n}+2\left(\frac{C_{e}}{C_{2}}\right)^{2 n}}{1+\left(\frac{C_{e}}{C_{1}}\right)^{n}+\left(\frac{C_{e}}{C_{2}}\right)^{2 n}}
$$


Where $\mathrm{C}_{1 / 2}, \mathrm{C}_{1}$ and $\mathrm{C}_{2}$ are the corresponding concentrations at half saturation, respectively. These three models were applied to correlate the MB adsorption data of CdSe-MSA nanocrystals and the fitting results suggested that the monolayer adsorption model $\left(\mathrm{R}^{2}=0.98\right.$ 0.99 and $\mathrm{RMSE}=1.84-3.49)$ was the best to interpret the adsorption mechanism of MB dye, see Figure 9 and Table 5. Note that the calculation of adsorption energy via this model was performed with the next equation(Atrous et al. 2019; Bouzid et al. 2016; Mohamed et al. 2018; Bouzid et al. 2019; Pang et al. 2020).

$$
\text { (Bouzid et al. 2019b) } \Delta E_{1}=R \cdot T \cdot \ln \left(\frac{C_{s}}{C_{1 / 2}}\right)
$$

where $\mathrm{C}_{\mathrm{s}}$ is the $\mathrm{MB}$ dye molecule solubility (i.e., $40 \mathrm{~g} / \mathrm{L}$ ), $R$ is the universal ideal gas constant $\left(8.314 \times 10^{-3} \mathrm{~kJ} / \mathrm{K} \cdot \mathrm{mol}\right)$ and $T(\mathrm{~K})$ is the absolute value of adsorption temperature. The fitted parameters of this statistical physics model are given in Table 6.

Overall, the number of adsorbed dye molecules per adsorption site of CdSe-MSA nanocrystals increased with temperature. This result indicated that there was an aggregation process where the formation of MB dimmers in the solution and a multi-molecular adsorption process $(n>1)$ could be expected. Therefore, a non-parallel adsorption orientation prevailed for the removal of this dye molecule. The density of adsorption sites $D_{M}$ decreased with temperature. Note that if the number of adsorbed MB dye molecules per adsorption site increased, the space in the CdSe-MSA nanocrystals surface reduced and, consequently, the number of adsorption sites available for dye removal became limited. The adsorption capacities at saturation $\left(q_{s a t}\right)$ decreased as a function of aqueous solution temperature from $27.22 \mathrm{mg} / \mathrm{g}$ at $298 \mathrm{~K}$ to $23.92 \mathrm{mg} / \mathrm{g}$ at $318 \mathrm{~K}$, thus indicating an exothermic adsorption. Table 6 shows that the adsorption energies ranged from 24.38 to $26.04 \mathrm{~kJ} / \mathrm{mol}$ thus suggesting the presence of physical interactions between MB dye molecules and the CdSe-MSA nanocrystals surface. It could be expected that weak electrostatic forces and hydrogen-bond interactions were involved in the adsorption of MB molecules on the functional groups of CdSe-MSA nanocrystals.

Thermodynamic functions of this adsorption process were calculated with the statistical physics model: the configurational entropy $\left(S_{a}\right)$, Gibbs free energy $\left(G_{a}\right)$ and the enthalpy $\left(H_{a}\right)$. Specifically, the configurational entropy is given by the following equation(Mohamed et al. 2018; Bouzid et al. 2016): 


$$
\frac{S_{a}}{K_{B}}=D_{M}\left(\ln \left(1+\left(\frac{C_{e}}{C_{1 / 2}}\right)^{n}\right)-\frac{\left(\frac{C_{e}}{C_{1 / 2}}\right)^{n} \cdot \ln \left(\left(\frac{C_{e}}{C_{1 / 2}}\right)^{n}\right)}{\left(1+\left(\frac{C_{e}}{C_{1 / 2}}\right)^{n}\right)}\right)
$$

483

484

485

$$
\frac{G_{a}}{K_{B} \cdot T}=\log \left(\frac{C_{e}}{Z_{V}}\right)\left(\frac{n \cdot D_{M}}{\left(1+\left(\frac{C_{1 / 2}}{C_{e}}\right)^{n}\right)}\right)
$$

The Gibbs free energy $\left(\mathrm{G}_{\mathrm{a}}\right)$ is defined by(Mohamed et al. 2018; Bouzid et al. 2016):

Where $Z_{v}$ represents the translation partition function per unit of volume(Bouzid et al. 2016; Mohamed et al. 2018; Bouzid et al. 2016; Pang et al. 2020).Finally, the adsorption enthalpy $\mathrm{H}_{\mathrm{a}}$ is given by(Bouzid et al. 2016; Mohamed et al. 2018; Bouzid et al. 2016; Pang et al. 2020):

$$
\frac{H_{a}}{K_{B} \cdot T}=\log \left(\frac{C_{e}}{Z_{V}}\right)\left(\frac{D_{M}\left(\frac{C_{e}}{C_{1 / 2}}\right)^{n}}{\left(1+\left(\frac{C_{e}}{C_{1 / 2}}\right)^{n}\right)}\right)-D_{M} \cdot \ln \left(1+\left(\frac{C_{e}}{C_{1 / 2}}\right)^{n}\right) \cdot \frac{\left(\frac{C_{e}}{C_{1 / 2}}\right)^{n}}{\left(1+\left(\frac{C_{e}}{C_{1 / 2}}\right)^{n}\right)}+\frac{D_{M}\left(\frac{C_{e}}{C_{1 / 2}}\right)^{n}}{\left(1+\left(\frac{C_{e}}{C_{1 / 2}}\right)^{n}\right)}
$$

The variation of these thermodynamic functions with respect to the equilibrium $\mathrm{MB}$ concentration at different temperatures is illustrated in Figure 10.

The evolution of configurational entropy $\left(S_{a}\right)$ showed one stationary point corresponding to $\mathrm{C}_{1 / 2}$ where the disorder is maximum when half of the density of adsorption sites $\left(\mathrm{D}_{\mathrm{M}}\right)$ of CdSe-MSA nanocrystals surface were occupied. Note that if $\mathrm{C}_{\mathrm{e}}<\mathrm{C}_{1 / 2}$, the disorder increased causing that $\mathrm{MB}$ molecules had several adsorption sites to interact during the adsorption process on CdSe-MSA nanocrystals. This entropy decreased until all the adsorption sites of CdSe-MSA nanocrystals were fully occupied. The adsorption temperature reduced the configurational entropy, see Figure 10. (a).

For the case of Gibbs free enthalpy, $\Delta \mathrm{G}_{\mathrm{a}}<0$ thus indicating that the adsorption of $\mathrm{MB}$ molecules on CdSe-MSA nanocrystals was a thermodynamic spontaneous process (see Figure 10. (b)). $G_{a}$ decreased with the $M B$ concentration and solution temperature and it was confirmed that the adsorption feasibility of MB on CdSe-MSA nanocrystals was affected by the thermal agitation effect. Finally, Figure 10 (c)shows that all calculated values of the adsorption enthalpy were negative, which confirmed the thermodynamic nature of an exothermic process(Sghaier et al. 2021).The adsorption enthalpy increased as a function of the solution temperature where this behavior could be due to increment of the thermal 
collisions produced by the MB adsorption on the surface of CdSe-MSA nanocrystals. The adsorption enthalpy values $\left(\mathrm{H}_{\mathrm{a}}\right)$ were lower than $40 \mathrm{~kJ} / \mathrm{mol}$. As stated, the hydrogen bond could be the main interaction during MB adsorption.

\subsection{Photocatalytic degradation of MB dye using solar and UV irradiations}

As stated, the photocatalytic activity of CdSe-MSA nanocrystals was evaluated in MB degradation using a contact time of $10 \mathrm{~min}, 30 \mathrm{~mL}$ of solution at $\mathrm{pH} 7$ and $298 \mathrm{~K}$. These photocatalytic degradation studies were performed using visible light and sunlight. It is important to recall that the CdSe-MSA nanocrystals showed an adsorption capacity up to $23.9 \mathrm{mg} / \mathrm{g}$ within $10 \mathrm{~min}$ of contact time to reach the adsorption-desorption equilibrium phase. Figure 11 displays the absorption spectra of $\mathrm{MB}$ without nanocatalyst versus time under visible-light irradiation. The blank test showed a slight dye degradation of $20 \%$ after $2 \mathrm{~h}$ of irradiation thus confirming that the removal of this organic molecule by direct photolysis was not effective. Note that only a very small decrement of dye concentration was observed when the solution was exposed to sunlight under the same conditions but in the absence of nanocatalyst. Therefore, there was no significant dye degradation by photolysis during the whole test period.

Figures 12 and 13 report the evolution of the absorption spectra and MB photodegradation versus time under visible light with the CdSe-MSA nanocatalysts. As soon as the solution was exposed to visible light with the presence of nanocatalyst, the color of MB dye became faint and the maximum peak at $664 \mathrm{~nm}$ observed in the absorption spectra decreased quickly with respect to the irradiation time. $\mathrm{MB}$ concentration in the solution reached to its half after only 60 min (i.e., the half-life degradation time).The degradation efficiencies for CdSe-MSA nanocrystals were $60 \%$ after $10 \mathrm{~min}$ and the degradation rate increased rapidly up to $97 \%$ after 120min. According to different studies (SUlAbideen and Teng 2018; Gómez-Avilés et al. 2019), the impact of the initial concentration on the photocatalytic photodegradation rate of organic compounds can be described by a pseudo-first-order kinetic. Figure14 shows the linear plots of $\ln \left(\mathrm{C} / \mathrm{C}_{0}\right)$ versus time for the $\mathrm{MB}$ photodegradation with CdSe-MSA nanocrystals under visible light after $120 \mathrm{~min}$. Results of data fitting $\left(\mathrm{R}^{2}=0.97\right)$ confirmed that this photodegradation followed a pseudo-first-order kinetics. The apparent photodegradation rate $\left(k_{a p p}\right)$ was calculated from the slope of $\ln \left(\mathrm{C}_{0} / \mathrm{C}\right)$ versus $t$ and was 0.01 $\min ^{-1}$.

Herein, it is important to remark that the solar photocatalytic treatment is an attractive method for the wastewater depollution because it is an effective, simple and economical 
system using renewable energy(Belver et al. 2020; Borges et al. 2016).Therefore, the

541 photodegradation experiment with sun light was similar to that performed under UV 542 irradiation. When the adsorption equilibrium was reached, the dye solution was submitted 543 directly under solar illumination on a sunny day between 11AM and 3 PM. Figures15 and 16

544

545

546

547

548

549

550

551

552

553

554

555

556

557

558

559

560

561

562

563

564

565

566

567

568

569

570

571 report the evolution of the absorption spectra and MB photodegradation versus time under visible light with the CdSe-MSA nanocatalyst. MB spectrum showed that the main absorption band responsible for the blue color disappeared completely after $240 \mathrm{~min}$ with an almost total degradation rate of $99 \%$.This degradation efficiency was almost five times greater than that obtained in the case of blank tests. The apparent degradation rate constant was illustrated, see Figure 17.

Note that sunlight required $240 \mathrm{~min}$ to reach $99 \% \mathrm{MB}$ photodegradation, while UV irradiation required $120 \mathrm{~min}$ to obtain a $97 \% \mathrm{MB}$ photodegradation, see Figure 18.Under sunlight irradiation, this nanocatalyst absorbed the totality of the solar spectrum in the visible range because of its gap energy, which allowed their activation only with the available visible irradiation thus representing nearly $40 \%$ of the solar resource $(400 \mathrm{~W} / \mathrm{m})$.In contrast, UV radiation represented only $5 \%\left(50 \mathrm{~W} / \mathrm{m}^{2}\right)$ of the total available solar flux received at the surface of the earth in the most favorable sunlight conditions(Kopp and Lean 2011). This high efficiency may be due to the high absorption of nanocrystals in the visible range in addition to their specific surface area and crystallinity, which contributed to the availability of adsorption sites(Dake et al. 2020). The band gap of CdSe-MSA nanocrystals favored the absorption of visible light. These results showed that these nanocrystals could be promising candidates for photocatalytic applications under solar light.

The processes involved in the photocatalytic degradation of this organic dye can be understood as follows. The electrons were excited by visible light irradiation and generation of hole $(h+)$ in the valence band to conduction band, see Equation (27). Both electrons and $\mathrm{h}^{+}$ transferred to the crystals surface and reacted with molecular oxygen $\left(\mathrm{O}_{2}\right)$ and $\mathrm{H}_{2} \mathrm{O}$ molecules to produce free hydroxyl radical $\left({ }^{\circ} \mathrm{OH}\right)$ and superoxide radical anion $\left({ }^{\circ} \mathrm{O}_{2}{ }^{-}\right)$, see Equations (28)-(30).These free radicals worked as strong oxidizing agent as well as active site for photocatalytic degradation of organic pollutants. These phenomena can be summarized in the following equations(Ramki et al. 2020):

$$
C d S e-M S A+h v \rightarrow C d S e-M S A\left[e^{-}(C B)+h^{+}(V B)\right]
$$

$$
h^{+}(\mathrm{VB})+\mathrm{OH}^{-} \rightarrow^{*} \mathrm{OH}
$$




$$
\mathrm{O}_{2}+e^{-}(\mathrm{CB}) \rightarrow^{*} \mathrm{O}_{2}^{-}
$$

$$
{ }^{*} \mathrm{O}_{2}{ }^{-}+{ }^{*} \mathrm{OH}+\mathrm{MB} \rightarrow \mathrm{CO}_{2}+\mathrm{H}_{2} \mathrm{O}+\text { Degradation products }
$$

575 The scheme for MB removal by the synergistic effect of adsorption and photodegradation is presented in Figure 19.As indicated, the highly reactive hydroxyl radicals $\left({ }^{\circ} \mathrm{OH}\right)$ and superoxide radicals $\left({ }^{\circ} \mathrm{O}_{2}^{-}\right)$reacted with $\mathrm{MB}$ dye adsorbed on CdSe nanocrystals and leaded to its degradation/decoloration resulting in its colorless form by converting it into $\mathrm{CO}_{2}, \mathrm{H}_{2} \mathrm{O}$ and other degradation products, see Equation (31).The dye degradation rate depended on the morphology and crystallinity of the photocatalysts. Nanomaterials with large surface area and high crystallinity can increase the number of active sites and promote the separation efficiency of the electron-hole pairs in the photocatalytic reactions(Dake et al. 2020; Kuriakose et al. 2014). The emission of blue-green $(400-550 \mathrm{~nm})$ indicates the density of selenium vacancies $\left(\mathrm{S}_{\mathrm{e}}\right)$ and interstitial of cadmium $\left(\mathrm{I}_{\mathrm{cd}}\right)$ to tune the luminescent properties at visible light emission region. Consequently, the ions defects of crystal lattice can absorb light at visible region to create electron-hole pairs responsible for photodegradation process of dyes in nanocrystals catalyst active surface. This interstitial defect can introduce different energy levels within the forbidden gap of CdSe-MSA catalyst. The excited electrons trapped and slowed down the recombination by vacancies and interstitial of which energy levels can involve in the valence and conduction bands of CdSe-MSA, acting as trap centers of the photo-generated charges. The trap of charge carriers can decrease the recombination rate of electron-hole pairs and increase the lifetime of charge carriers. Consequently, the photocatalytic activity of nanocrystals was increased by these defects, which could facilitate the transfer of the photo-generated carriers by trapping the excited electrons and restrain the electron-hole recombination. During this process, the photo-generated charges participated in the production of active hydroxyl radicals and superoxide anion radicals and, consequently, these radicals could convert MB molecules into less harmful degraded products. 


\section{Conclusions}

CdSe-MSA nanocrystals were successfully synthesized via the colloidal method and the contribution of adsorption and photocatalytic of MB dye molecule from aqueous solution was investigated. Based on XRD and HRTEM measurements, a cubic phase structure was obtained. HRTEM results indicate that the CdSe-MSA distributes uniformly and the size is nearly equal to $3.7 \pm 0.1 \mathrm{~nm}$. The surface optical phonon modes (SO) and longitudinal optical phonon (IO) can be used as a gauge to infer at the interface of nanocrystals-ligand. Kinetics and isotherms were quantified to determine the impact of adsorption of $\mathrm{MB}$ on tested nanocrystals. Results showed spontaneous exothermic adsorption thus obtaining adsorption capacities up to $23.9 \mathrm{mg} / \mathrm{g}$. Statistical physics calculations were used to analyze the steric and energetic parameters associated to the $\mathrm{MB}$ adsorption on the nanocrystals surface. It was found that this adsorption process was governed mainly by electrostatic interactions and hydrogen bonding. The adsorption capacity of CdSe-MSA nanocrystals favored the direct interaction of photo-generated electrons with adsorbed MB molecules and, hence, facilitated a fast photodegradation. CdSe-MSA nanocrystals showed a remarkable UV-light photocatalytic activity for MB dye with a conversion rate of $80 \%$ in $60 \mathrm{~min}$. Results of this study indicated that the semiconductor nanocrystals can be used as an effective material for dye removal from wastewaters with effective photodegradation activity under sunlight. This approach could be a sustainable and cost-effective treatment system for the remediation of water polluted by organic compounds like dye.

\section{Author's contribution:}

Naim Bel Haj Mohamed: Visualization, Writing - review \& editing; Conceptualization, Methodology

Sabri Ouni: Writing - original draft, Visualization, Conceptualization, Methodology

Mohamed bouzid: Resources, Writing - review \& editing

Mohamed bouzidi: Resources, Writing - review \& editing Adrian Bonilla-Petriciolet: Writing - Reviewing and Editing

Mohamed Haouari: Writing - Reviewing and Editing, Visualization, Supervision

\section{Funding:}

The authors declare that they have no known competing financial interests or personal relationships that could have appeared to influence the work reported in this paper.

Availability of data and materials: Data and materials are contained within the article 
637 Ethics approval and consent to participate: Not applicable for this study.

638 Consent to publish: All authors consent to this publication.

639 Competing interests: The authors declare no competing interests.

\section{References:}

641 Abd El-sadek MS, Babu SM (2011) A controlled approach for synthesizing CdTe@CrOOH (core-shell)

642 composite nanoparticles. CurrAppl Phys 11:926-932. https://doi.org/10.1016/j.cap.2010.12.022

643 Abu-Alsoud GF, Hawboldt KA, Bottaro CS (2020) Comparison of Four Adsorption Isotherm Models for 644 Characterizing Molecular Recognition of Individual Phenolic Compounds in Porous Tailor-Made

645 Molecularly Imprinted Polymer Films. ACS Appl Mater Interfaces 12:11998-12009.

646 https://doi.org/10.1021/acsami.9b21493

647 Arivarasan A, Bharathi S, Ezhilarasi S, et al (2019) Photovoltaic Performances of Yb Doped CdTe QDs 648 Sensitized TiO2 Photoanodes for Solar cell Applications. J InorgOrganometPolym Mater 29:859-868. 649 https://doi.org/10.1007/s10904-018-01060-5

650 Asfaram A, Ghaedi M, Hajati S, et al (2015) Rapid removal of Auramine-O and Methylene blue by

651 ZnS:Cu nanoparticles loaded on activated carbon: A response surface methodology approach. J

652 Taiwan Inst ChemEng 53:80-91. https://doi.org/10.1016/j.jtice.2015.02.026

653 Atrous M, Sellaoui L, Bouzid M, et al (2019) Adsorption of dyes acid red 1 and acid green 25 on 654 grafted clay: Modeling and statistical physics interpretation. J Mol Liq 294:111610.

655 https://doi.org/10.1016/j.molliq.2019.111610

656

657

658

659

660

661

662

663

664

665

666

667

668

669

670

Azha SF, Sellaoui L, Engku Yunus EH, et al (2019) Iron-modified composite adsorbent coating for azo dye removal and its regeneration by photo-Fenton process: Synthesis, characterization and adsorption mechanism interpretation. ChemEng J 361:31-40.

https://doi.org/10.1016/j.cej.2018.12.050

Bacherikov YY, Davydenko MO, Dmytruk AM, et al (2006) CdSe nanoparticles grown with different chelates

Bel Haj Mohamed N, Ben Brahim N, Mrad R, et al (2018) Use of MPA-capped CdS quantum dots for sensitive detection and quantification of $\mathrm{Co} 2+$ ions in aqueous solution. Anal Chim Acta 1028:50-58. https://doi.org/10.1016/j.aca.2018.04.041

Bel Haj Mohamed N, Bouzidi M, Ben brahim N, et al (2021) Impact of the stacking fault and surface defects states of colloidal CdSe nanocrystals on the removal of reactive black 5. Mater SciEng $B$ 265:115029. https://doi.org/10.1016/j.mseb.2020.115029

Bel Haj Mohamed N, Haouari M, Zaaboub Z, et al (2014) Effect of surface on the optical structure and thermal properties of organically capped CdS nanoparticles. J Phys Chem Solids 75:936-944.

https://doi.org/10.1016/j.jpcs.2014.03.007 
Belver C, Bedia J, Peñas-Garzón M, et al (2020) 3 - Structured photocatalysts for the removal of emerging contaminants under visible or solar light. In: Sacco O, Vaiano V (eds) Visible Light Active Structured Photocatalysts for the Removal of Emerging Contaminants. Elsevier, pp 41-98

Ben Brahim N, Bel Haj Mohamed N, Poggi M, et al (2017) Interaction of I-cysteine functionalized CdSe quantum dots with metallic cations and selective binding of cobalt in water probed by fluorescence. Sens Actuators B Chem 243:489-499. https://doi.org/10.1016/j.snb.2016.12.003

Borges ME, Sierra M, Méndez-Ramos J, et al (2016) Solar degradation of contaminants in water: TiO2 solar photocatalysis assisted by up-conversion luminescent materials. Sol Energy Mater Sol Cells 155:194-201. https://doi.org/10.1016/j.solmat.2016.06.010

Bouzid M, Bouaziz N, Torkia YB, Lamine AB (2019a) Statistical physics modeling of ethanol adsorption onto the phenol resin based adsorbents: Stereographic, energetic and thermodynamic investigations. J Mol Liq 283:674-687. https://doi.org/10.1016/j.molliq.2019.03.129

Bouzid M, Bouaziz N, Torkia YB, Lamine AB (2019b) Statistical physics modeling of ethanol adsorption onto the phenol resin based adsorbents: Stereographic, energetic and thermodynamic investigations. J Mol Liq 283:674-687. https://doi.org/10.1016/j.molliq.2019.03.129

Bouzid M, Sellaoui L, Khalfaoui M, et al (2016) Adsorption of ethanol onto activated carbon: Modeling and consequent interpretations based on statistical physics treatment. Phys Stat Mech Its Appl 444:853-869. https://doi.org/10.1016/j.physa.2015.09.097

Chaparro AM, Martínez MA, Guillén C, et al (2000) SnO 2 substrate effects on the morphology and composition of chemical bath deposited ZnSe thin films. Thin Solid Films 361-362:177-182. https://doi.org/10.1016/S0040-6090(99)00791-9

Cheng L, Xiang Q, Liao Y, Zhang H (2018) CdS-Based photocatalysts. Energy Environ Sci 11:1362-1391. https://doi.org/10.1039/C7EE03640J

Dake DV, Raskar ND, Mane VA, et al (2020) Exploring the role of defects on diverse properties of Crsubstituted ZnS nanostructures for photocatalytic applications. Appl Phys A 126:640. https://doi.org/10.1007/s00339-020-03669-1

Deng Y, Zhao R (2015) Advanced Oxidation Processes (AOPs) in Wastewater Treatment. CurrPollut Rep 1:167-176. https://doi.org/10.1007/s40726-015-0015-z

Freundlich H (1907) Über die Adsorption in Lösungen. Z Für Phys Chem 57U:385-470. https://doi.org/10.1515/zpch-1907-5723

Gaponenko SV (1998) Optical Properties of Semiconductor Nanocrystals. Cambridge University Press

Ghasemi M, Ghasemi N, Zahedi G, et al (2014) Kinetic and equilibrium study of Ni(II) sorption from aqueous solutions onto Peganumharmala-L. Int J Environ SciTechnol 11:1835-1844.

https://doi.org/10.1007/s13762-014-0617-9

Gómez-Avilés A, Peñas-Garzón M, Bedia J, et al (2019) Mixed Ti-Zr metal-organic-frameworks for the photodegradation of acetaminophen under solar irradiation. Appl Catal B Environ 253:253-262. https://doi.org/10.1016/j.apcatb.2019.04.040 
Guo H, Ke Y, Wang D, et al (2013) Efficient adsorption and photocatalytic degradation of Congo red onto hydrothermally synthesized NiS nanoparticles. J Nanoparticle Res 15:1475.

https://doi.org/10.1007/s11051-013-1475-y

Han K, Peng X-L, Li F, Yao M-M (2018) SnO2 Composite Films for Enhanced Photocatalytic Activities. Catalysts 8:453. https://doi.org/10.3390/catal8100453

Hashimoto K, Irie H, Fujishima A (2005) $\mathrm{TiO}_{2}$ Photocatalysis: A Historical Overview and Future Prospects. Jpn J Appl Phys 44:8269-8285. https://doi.org/10.1143/JJAP.44.8269

Ho YS, McKay G (1999) Pseudo-second order model for sorption processes. Process Biochem 34:451465. https://doi.org/10.1016/S0032-9592(98)00112-5

Hu H, Yang M, Dang J (2005) Treatment of strong acid dye wastewater by solvent extraction. Sep PurifTechnol 42:129-136. https://doi.org/10.1016/j.seppur.2004.07.002

Huang C, Liu S, Chen T, Li Y (2008) A new approach for quantitative determination of glucose by using CdSe/ZnS quantum dots. Sens Actuators B Chem 130:338-342.

https://doi.org/10.1016/j.snb.2007.08.021

Ilgin P, Ozay H, Ozay O (2019) Selective adsorption of cationic dyes from colored noxious effluent using a novel N-tert-butylmaleamic acid based hydrogels. React FunctPolym 142:189-198. https://doi.org/10.1016/j.reactfunctpolym.2019.06.018

Im SH, Lee YH, Seok SI (2010) Photoelectrochemical solar cells fabricated from porous CdSe and CdS layers. Electrochimica Acta 55:5665-5669. https://doi.org/10.1016/j.electacta.2010.04.106

Jabeen U, Shah SM, Khan SU (2017) Photo catalytic degradation of Alizarin red S using ZnS and cadmium doped ZnS nanoparticles under unfiltered sunlight. Surf Interfaces 6:40-49. https://doi.org/10.1016/j.surfin.2016.11.002

Jaseela PK, Garvasis J, Joseph A (2019) Selective adsorption of methylene blue (MB) dye from aqueous mixture of $\mathrm{MB}$ and methyl orange (MO) using mesoporous titania (TiO2) - poly vinyl alcohol (PVA) nanocomposite. J Mol Liq 286:110908. https://doi.org/10.1016/j.molliq.2019.110908

Jung YW, Yoon JJ, Byun JS, Kim YD (2008) Dielectric function analysis of ZnSe and CdSe using parametric semiconductor model. Microelectron J 39:570-572.

https://doi.org/10.1016/j.mejo.2007.07.038

Kaur R, Kaur A, Umar A, et al (2019) Metal organic framework (MOF) porous octahedral nanocrystals of Cu-BTC: Synthesis, properties and enhanced adsorption properties. Mater Res Bull 109:124-133. https://doi.org/10.1016/j.materresbull.2018.07.025

Klimov VI, McBranch DW, Leatherdale CA, Bawendi MG (1999) Electron and hole relaxation pathways in semiconductor quantum dots. Phys Rev B 60:13740-13749.

https://doi.org/10.1103/PhysRevB.60.13740

Kopp G, Lean JL (2011) A new, lower value of total solar irradiance: Evidence and climate significance. Geophys Res Lett 38:. https://doi.org/10.1029/2010GL045777 
Kotkata MF, Masoud AE, Mohamed MB, Mahmoud EA (2009) Structural characterization of chemically synthesized CdSe nanoparticles. Phys E Low-DimensSyst Nanostructures 41:640-645. https://doi.org/10.1016/j.physe.2008.10.019

Kuriakose S, Satpati B, Mohapatra S (2014) Enhanced photocatalytic activity of Co doped ZnO nanodisks and nanorods prepared by a facile wet chemical method. Phys ChemChem Phys 16:12741. https://doi.org/10.1039/c4cp01315h

Lakshmipathy R, Kesarla MK, Nimmala AR, et al (2017) ZnS nanoparticles capped with watermelon rind extract and their potential application in dye degradation. Res Chemlntermed 43:1329-1339. https://doi.org/10.1007/s11164-016-2700-y

Langmuir I (1918) THE ADSORPTION OF GASES ON PLANE SURFACES OF GLASS, MICA AND PLATINUM. J Am ChemSoc 40:1361-1403. https://doi.org/10.1021/ja02242a004

Li Z, Hanafy H, Zhang L, et al (2020) Adsorption of congo red and methylene blue dyes on an ashitaba waste and a walnut shell-based activated carbon from aqueous solutions: Experiments, characterization and physical interpretations. ChemEng J 388:124263.

https://doi.org/10.1016/j.cej.2020.124263

Liu C, Mao H, Zheng J, Zhang S (2017) Tight ultrafiltration membrane: Preparation and characterization of thermally resistant carboxylated cardo poly (arylene ether ketone)s (PAEK-COOH) tight ultrafiltration membrane for dye removal. J MembrSci 530:1-10. https://doi.org/10.1016/j.memsci.2017.02.005

Lo S, Lin C, Wu C, Hsieh P (2004) Capability of coupled CdSe/TiO for photocatalytic degradation of 4chlorophenol. J Hazard Mater 114:183-190. https://doi.org/10.1016/j.jhazmat.2004.08.007

Meinardi F, Bruni F, Brovelli S (2017) Luminescent solar concentrators for building-integrated photovoltaics. Nat Rev Mater 2:1-9. https://doi.org/10.1038/natrevmats.2017.72

Mohamed B, Qingyu Z, D. Moggridge G, Abdelmottaleb BL (2018) New insight in adsorption of pyridine on the two modified adsorbents types MN200 and MN500 by means of grand canonical ensemble. J Mol Liq 263:413-421. https://doi.org/10.1016/j.molliq.2018.05.008

Nataraj SK, Hosamani KM, Aminabhavi TM (2009) Nanofiltration and reverse osmosis thin film composite membrane module for the removal of dye and salts from the simulated mixtures. Desalination 249:12-17. https://doi.org/10.1016/j.desal.2009.06.008

Nath D, Singh F, Das R (2020) X-ray diffraction analysis by Williamson-Hall, Halder-Wagner and sizestrain plot methods of CdSe nanoparticles- a comparative study. Mater Chem Phys 239:122021. https://doi.org/10.1016/j.matchemphys.2019.122021

Nayak B, Samant A, Patel R, Misra PK (2017) Comprehensive Understanding of the Kinetics and Mechanism of Fluoride Removal over a Potent Nanocrystalline Hydroxyapatite Surface. ACS Omega 2:8118-8128. https://doi.org/10.1021/acsomega.7b00370 
Neto ESF, Dantas NO, da Silva SW, et al (2010) Confirming the lattice contraction in CdSe nanocrystals grown in a glass matrix by Raman scattering. J Raman Spectrosc 41:1302-1305.

https://doi.org/10.1002/jrs.2565

Ouni S, Bel Haj Mohamed N, Bouzidi M, et al (2021) High impact of thiol capped ZnS nanocrystals on the degradation of single and binary aqueous solutions of industrial azo dyes under sunlight. J Environ ChemEng 9:105915. https://doi.org/10.1016/j.jece.2021.105915

Pan B, Sun K, Xing B (2010) Adsorption kinetics of $17 \alpha$-ethinyl estradiol and bisphenol A on carbon nanomaterials. II. Concentration-dependence. J SoilsSediments 10:845-854.

https://doi.org/10.1007/s11368-009-0185-7

Pang X, Bouzid M, dos Santos JMN, et al (2020) Theoretical study of indigotine blue dye adsorption on CoFe2O4/chitosan magnetic composite via analytical model. Colloids Surf PhysicochemEng Asp 589:124467. https://doi.org/10.1016/j.colsurfa.2020.124467

Peng WQ, Qu SC, Cong GW, et al (2005) Optical and magnetic properties of ZnS nanoparticles doped with Mn2+. J Cryst Growth 282:179-185. https://doi.org/10.1016/j.jcrysgro.2005.05.005

R. S, A. P, Balakrishna GR, M. S. J (2018) La activated high surface area titania float for the adsorption of $\mathrm{Pb}$ (II) from aqueous media. New J Chem 42:1067-1077. https://doi.org/10.1039/C7NJ03358C

Ramki K, RajaPriya A, Sakthivel P, et al (2020) Rapid degradation of organic dyes under sunlight using tin-doped ZnS nanoparticles. J Mater Sci Mater Electron 31:8750-8760.

https://doi.org/10.1007/s10854-020-03410-x

Raskar ND, Dake DV, Mane VA, et al (2019) One step synthesis of vertically grown Mn-doped ZnO nanorods for photocatalytic application. J Mater Sci Mater Electron 30:10886-10899.

https://doi.org/10.1007/s10854-019-01433-7

Redlich O, Peterson DL (1959) A Useful Adsorption Isotherm. J Phys Chem 63:1024-1024. https://doi.org/10.1021/j150576a611

\section{S L (1898) ABOUT THE THEORY OF SO-CALLED ADSORPTION OF SOLUBLE SUBSTANCES. 24:1-39}

Safardoust-Hojaghan H, Salavati-Niasari M (2017) Degradation of methylene blue as a pollutant with $\mathrm{N}$-doped graphene quantum dot/titanium dioxide nanocomposite. J Clean Prod 148:31-36. https://doi.org/10.1016/j.jclepro.2017.01.169

Sajab MS, Chia CH, Zakaria S, Khiew PS (2013) Cationic and anionic modifications of oil palm empty fruit bunch fibers for the removal of dyes from aqueous solutions. BioresourTechnol 128:571-577. https://doi.org/10.1016/j.biortech.2012.11.010

Sauvé S, Desrosiers M (2014) A review of what is an emerging contaminant. Chem Cent J 8:15. https://doi.org/10.1186/1752-153X-8-15

Sghaier W, Ben Torkia Y, Bouzid M, Ben Lamine A (2021) CO2 adsorption investigation by statistical physics: Thermodynamic analysis for cooling cycle application. J Environ ChemEng 9:105108. https://doi.org/10.1016/j.jece.2021.105108 
Smida A, Zaaboub Z, Mohamed NBH, et al (2018) Photoluminescence behavior in the synthesized CdSe thin films deposited on ITO substrates. J Lumin 194:686-691. https://doi.org/10.1016/j.jlumin.2017.09.036

Soheyli E, Sahraei R, Nabiyouni G (2017) pH-dependent optical properties of N-acetyl-L-cysteinecapped ZnSe(S) nanocrystals with intense/stable emissions. J Nanoparticle Res 19:92. https://doi.org/10.1007/s11051-017-3792-z

Soltani N, Saion E, Mahmood Mat Yunus W, et al (2013) Photocatalytic degradation of methylene blue under visible light using PVP-capped ZnS and CdS nanoparticles. Sol Energy 97:147-154. https://doi.org/10.1016/j.solener.2013.08.023

Sousa JCG, Ribeiro AR, Barbosa MO, et al (2018) A review on environmental monitoring of water organic pollutants identified by EU guidelines. J Hazard Mater 344:146-162. https://doi.org/10.1016/j.jhazmat.2017.09.058

Stokes AR, Wilson AJC (1944) The diffraction of X rays by distorted crystal aggregates - I. Proc Phys Soc 56:174-181. https://doi.org/10.1088/0959-5309/56/3/303

Takeda N, Torimoto T, Sampath S, et al (1995) Effect of Inert Supports for Titanium Dioxide Loading on Enhancement of Photodecomposition Rate of Gaseous Propionaldehyde. J Phys Chem 99:99869991. https://doi.org/10.1021/j100024a047

Thandavan TMK, Gani SMA, Wong CS, Nor RM (2015) Evaluation of Williamson-Hall Strain and Stress Distribution in ZnO Nanowires Prepared Using Aliphatic Alcohol. J NondestructEval 34:14. https://doi.org/10.1007/s10921-015-0286-8

Todescato F, Minotto A, Signorini R, et al (2013) Investigation into the Heterostructure Interface of CdSe-Based Core-Shell Quantum Dots Using Surface-Enhanced Raman Spectroscopy. ACS Nano 7:6649-6657. https://doi.org/10.1021/nn402022z

Tschirner N, Lange H, Schliwa A, et al (2012) Interfacial Alloying in CdSe/CdS Heteronanocrystals: A Raman Spectroscopy Analysis. Chem Mater 24:311-318. https://doi.org/10.1021/cm202947n

UlAbideen Z, Teng F (2018) Enhanced photochemical activity and stability of ZnS by a simple alkaline treatment approach. CrystEngComm 20:7866-7879. https://doi.org/10.1039/C8CE01417E

Wang J, Zhao H, Zhu Y, Song Y (2017) Shape-Controlled Synthesis of CdSe Nanocrystals via a Programmed Microfluidic Process. J Phys Chem C 121:3567-3572.

https://doi.org/10.1021/acs.jpcc.6b10901

Wang Q, Ye F, Fang T, et al (2011) Bovine serum albumin-directed synthesis of biocompatible CdSe quantum dots and bacteria labeling. J Colloid Interface Sci 355:9-14.

https://doi.org/10.1016/j.jcis.2010.11.035

Williamson GK, Hall WH (1953) X-ray line broadening from filed aluminium and wolfram. Acta Metall 1:22-31. https://doi.org/10.1016/0001-6160(53)90006-6

Wu P-J, Stetsko YP, Tsuei K-D, et al (2007) Size dependence of tetrahedral bond lengths in CdSe nanocrystals. Appl Phys Lett 90:161911. https://doi.org/10.1063/1.2727559 
852 Yang J, Tang A, Zhou R, Xue J (2011) Effects of nanocrystal size and device aging on performance of 853 hybrid poly(3-hexylthiophene):CdSe nanocrystal solar cells. Sol Energy Mater Sol Cells95:476-482.

854 https://doi.org/10.1016/j.solmat.2010.09.005

855 Yazidi A, Sellaoui L, Dotto GL, et al (2019) Monolayer and multilayer adsorption of pharmaceuticals

856 on activated carbon: Application of advanced statistical physics models. J Mol Liq 283:276-286.

857 https://doi.org/10.1016/j.molliq.2019.03.101

858 Zhao Q, Xie Y, Zhang Z, Bai X (2007) Size-selective Synthesis of Zinc Sulfide Hierarchical Structures and 859 Their Photocatalytic Activity. CrystGrowth Des 7:153-158. https://doi.org/10.1021/cg060521j 
Figures

\section{Figure 1}

a: XRD patterns of CdSe-MSA nanocrystals b: Uniform deformation model plot for CdSe-MSA nanocrystals 


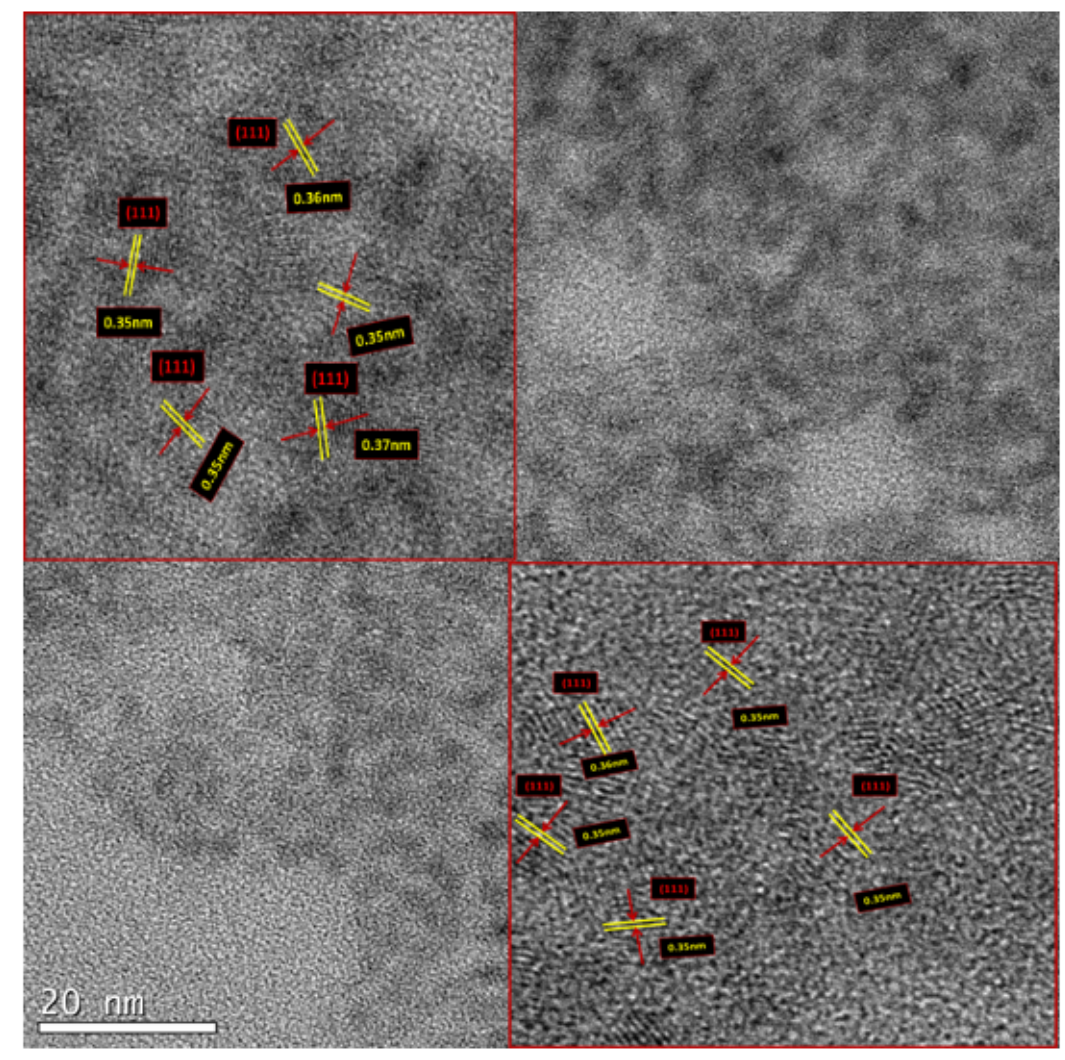

A

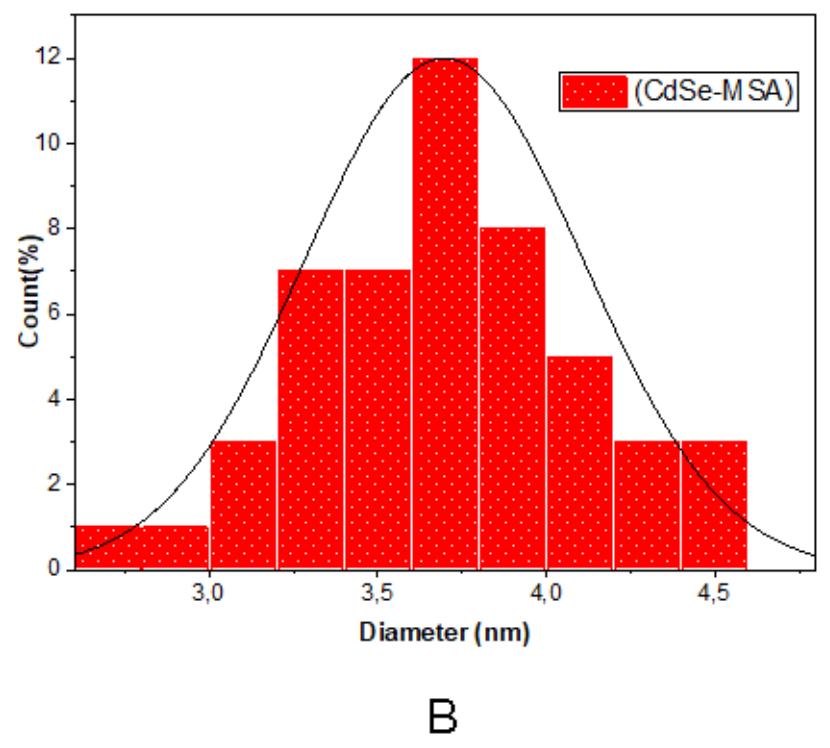

Figure 2

(a) TEM and HRTEM images (the lattice fringes with interplanar spacing of $3.5 \AA$ are clearly seen) and (b) histogram of size distribution of CdSe-MSA nanocrystals 


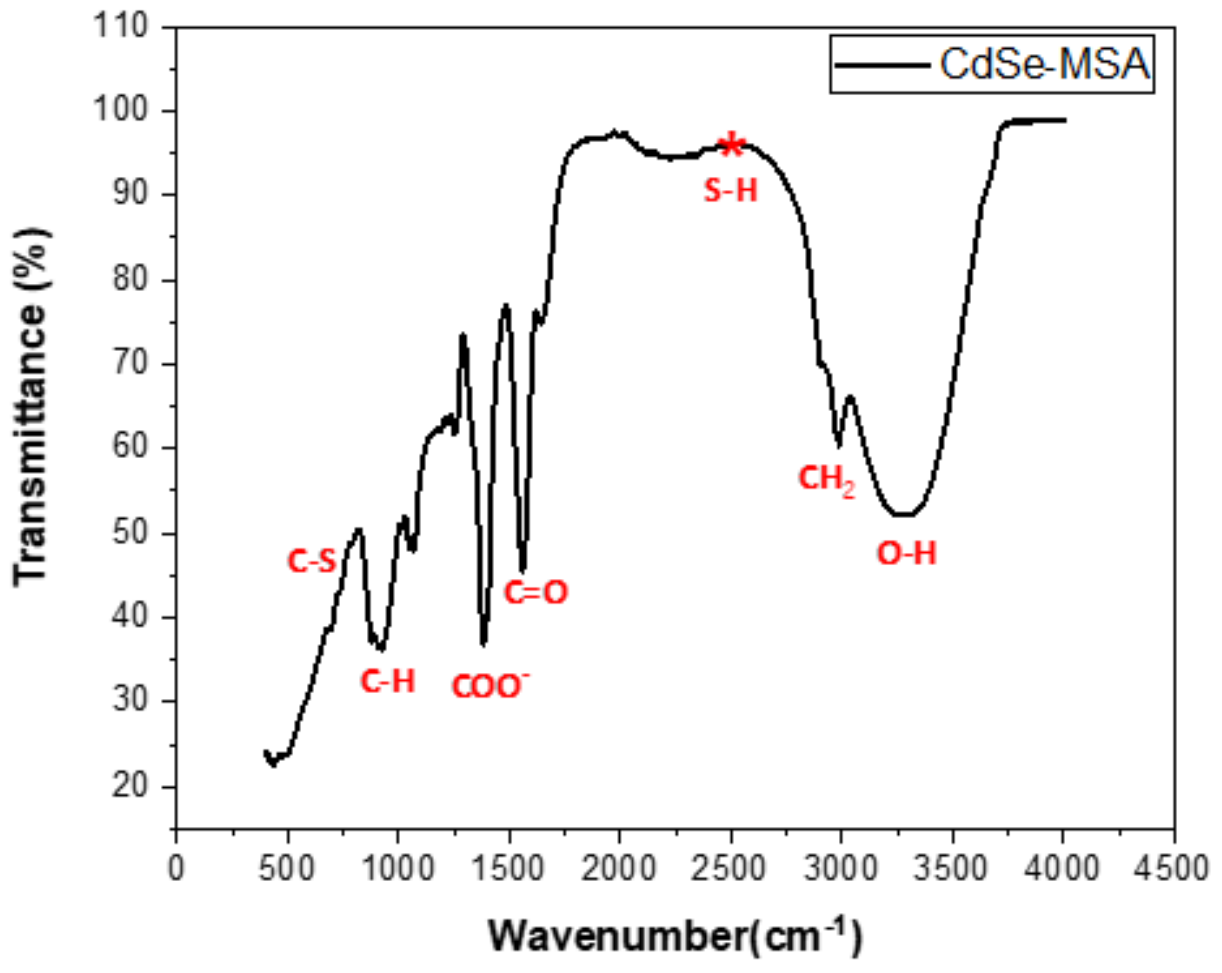

Figure 3

FT-IR spectrum of CdSe-MSA nanocrystals

Figure 4

Raman spectrum of CdSe-MSA nanocrystals 

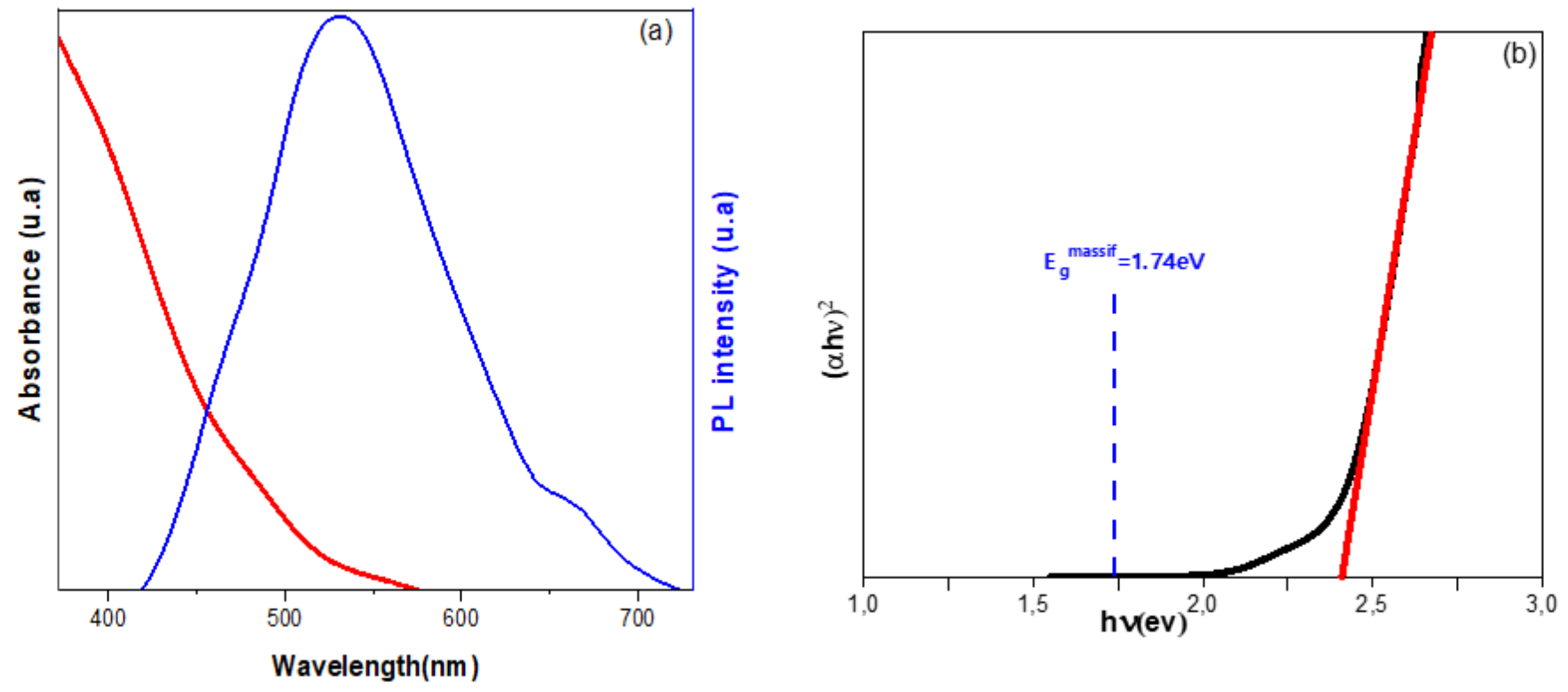

Figure 5

(a) UV-vis and PL spectrum and(b) Tauc plot of CdSe-MSA nanocrystals

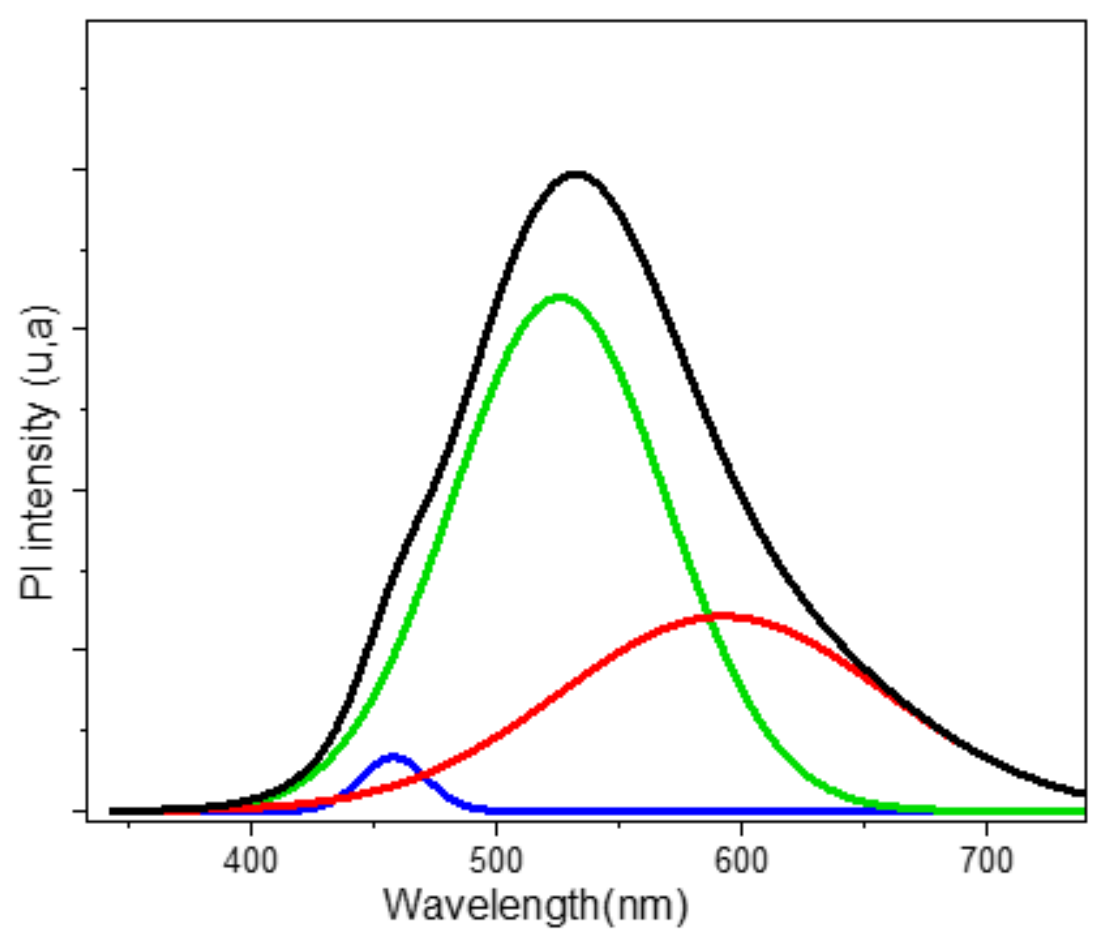

Figure 6

PL spectrum of CdSe-MSA nanocrystals 


\section{Figure 7}

Kinetics for the MB adsorption on CdSe-MSA nanocrystals and its modeling with the pseudo-first-order equation

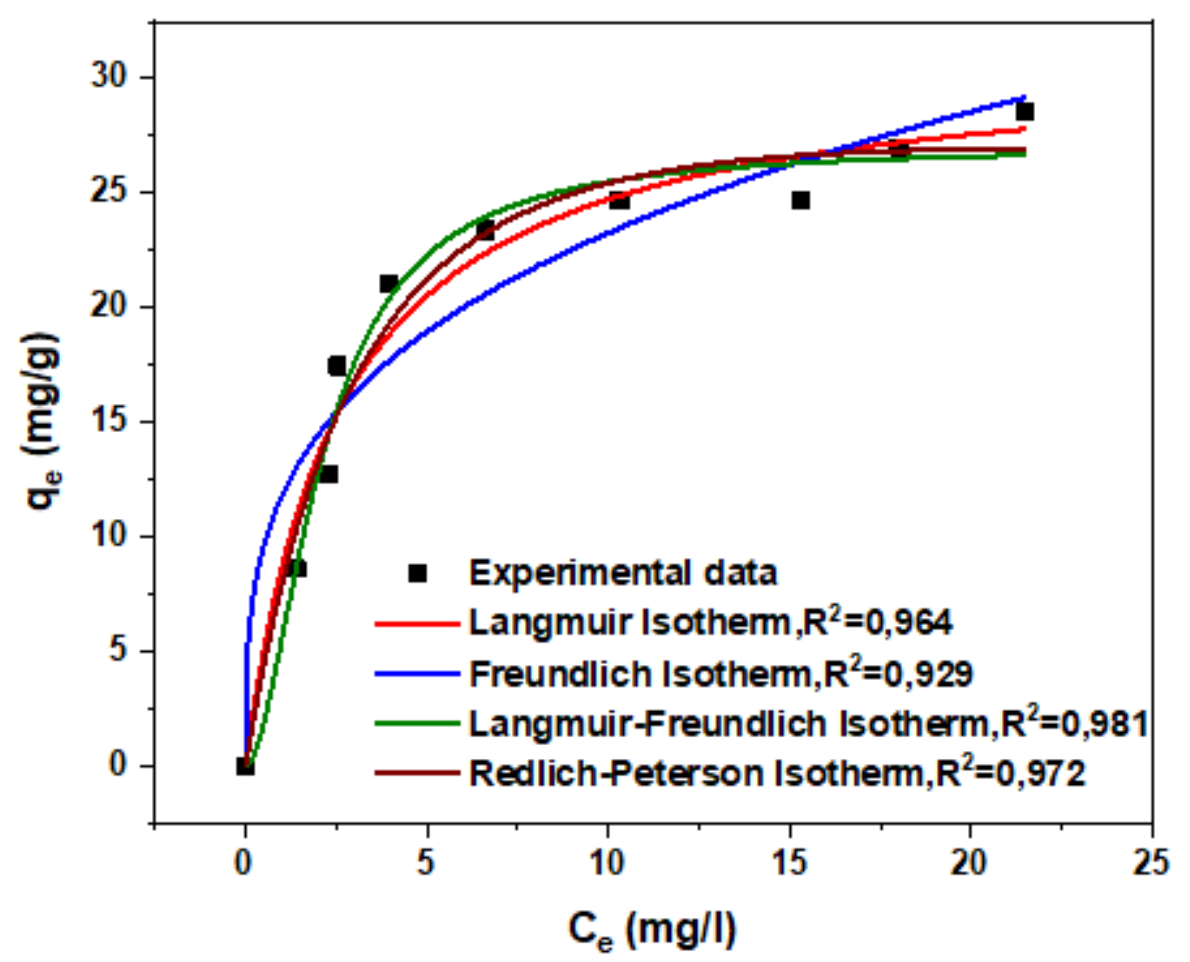

Figure 8

Adsorption isotherm of MB dye on CdSe-MSA nanocrystals at $\mathrm{pH} 7$ and $300 \mathrm{~K}$. 


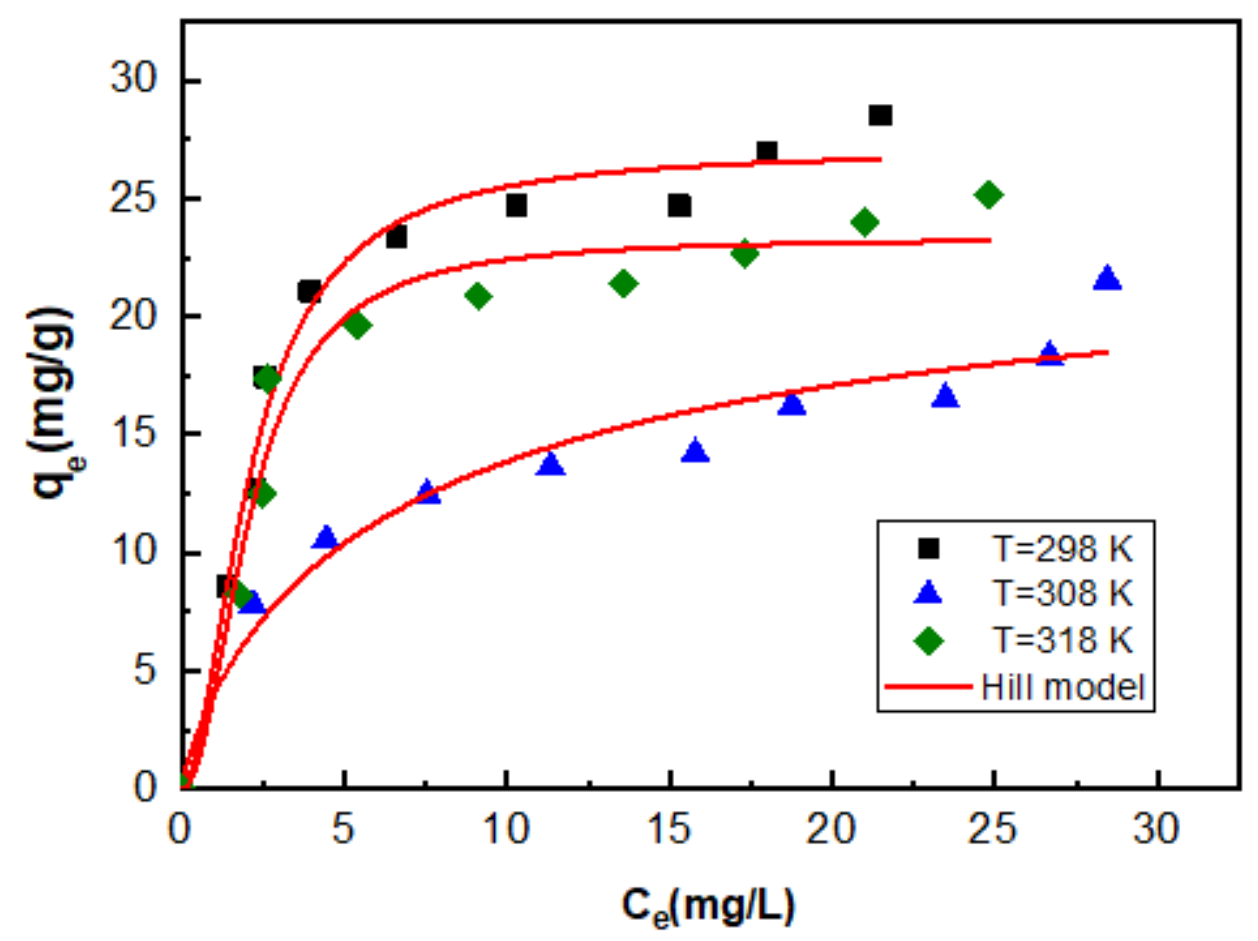

Figure 9

Adsorption isotherms of MB dye on CdSe-MSA nanocrystals at 298-318 K and pH7 and their statistical physics modeling

Figure 10

a) Configurational entropy, b) Gibbs free energy and c) adsorption enthalpy as function of equilibrium concentration of MB onto CdSe-MSA nanocrystals

\section{Figure 11}

The absorption spectrum of MB photodegradation without nanocrystals in visible-light irradiation

\section{Figure 12}

The absorption spectra of MB photodegradation in the presence of CdSe-MSA nanocrystals under UV light irradiation 


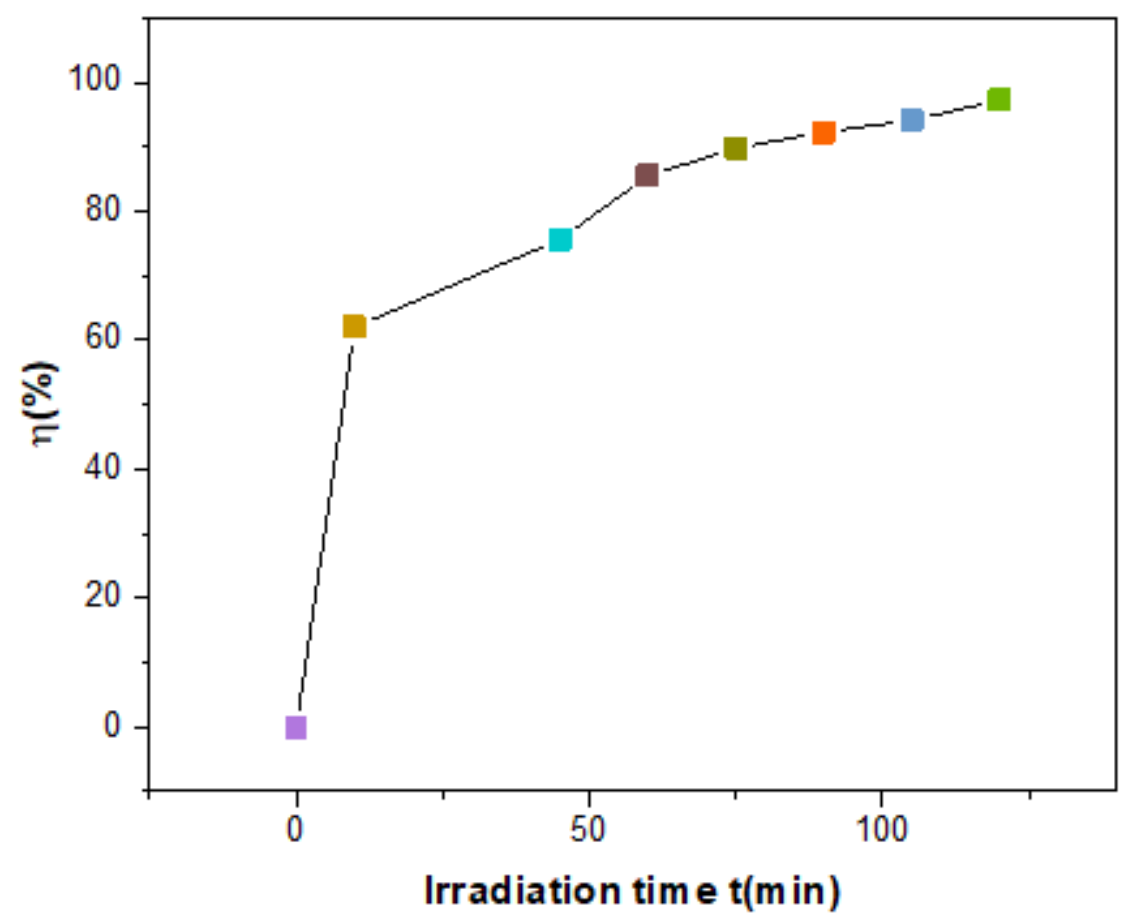

Figure 13

Photodegradation efficiency of MB dye by CdSe-MSA nanocrystals under UV light irradiation

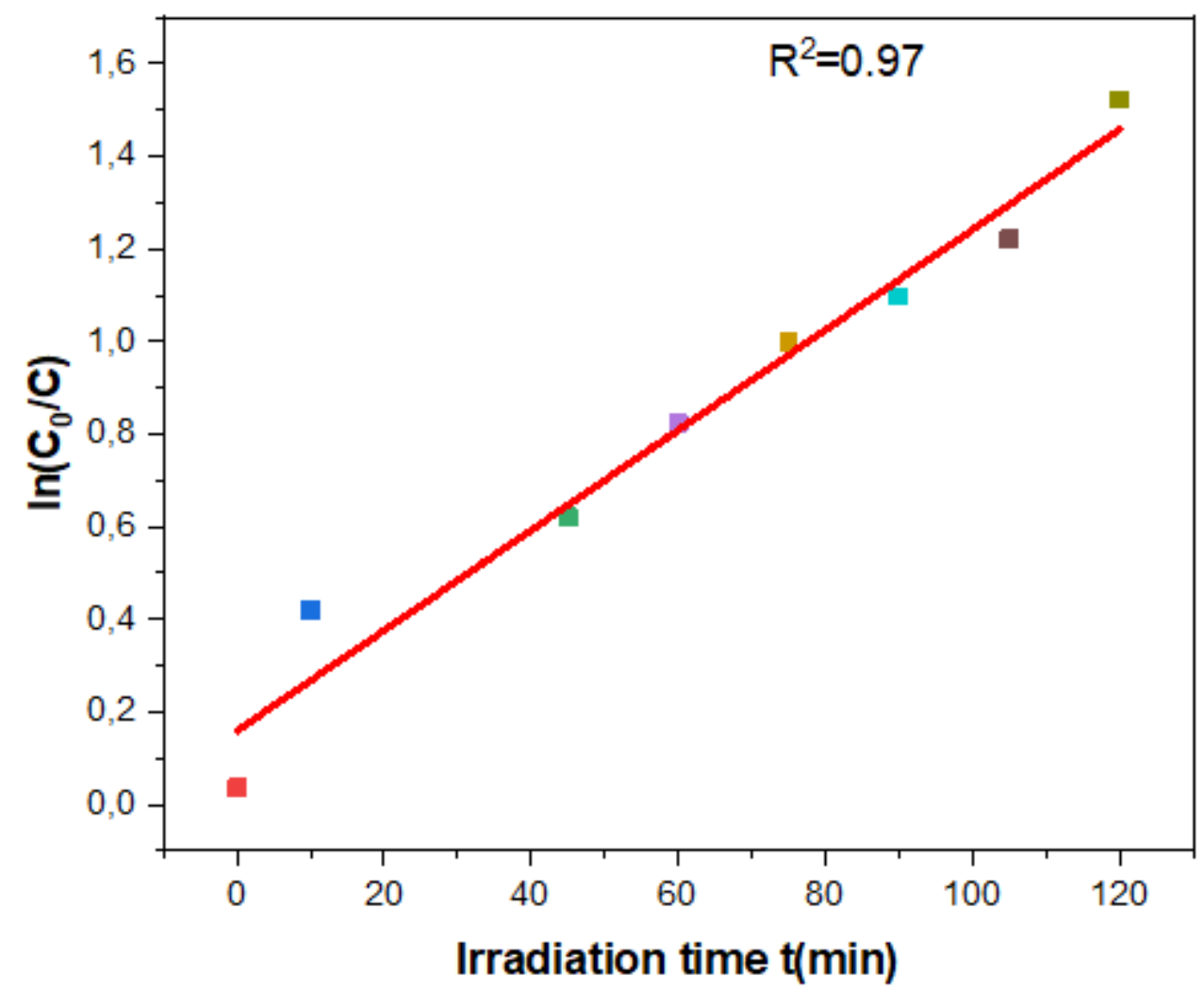


Figure 14

Linear plot of $\ln \left(\mathrm{C}_{0} / \mathrm{C}\right)$ versus time of MB degradation in the presence of CdSe-MSA nanocrystals under UV light irradiation

\section{Figure 15}

The absorption spectra of MB degradation in the presence of CdSe-MSA nanocrystals under solar light irradiation.

Figure 16

Photodegradation efficiency of MB dye by CdSe-MSA nanocrystals under solar light irradiation.

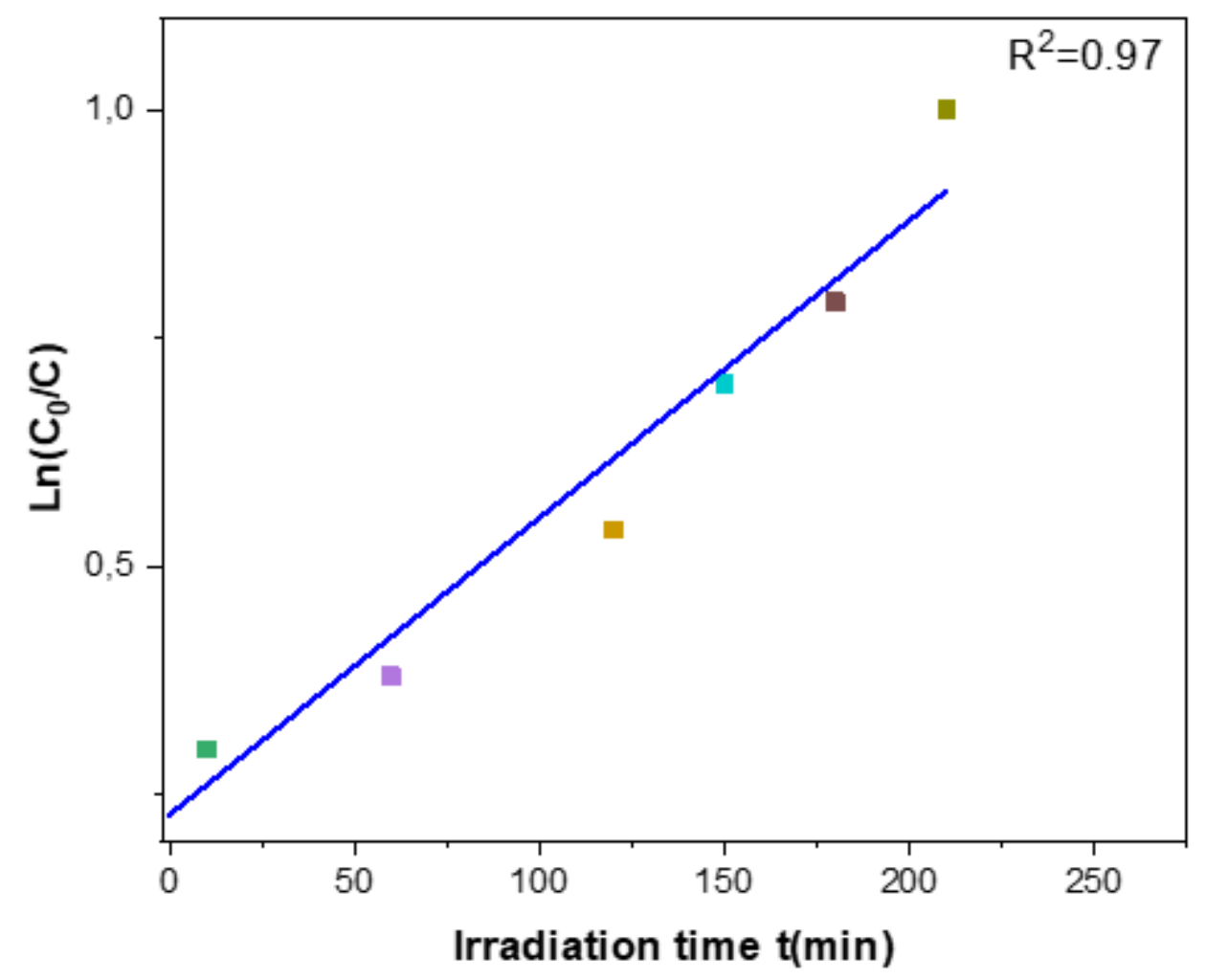

Figure 17

Linear plot of $\ln \left(\mathrm{C}_{0} / \mathrm{C}\right)$ versus time of MB degradation in the presence of CdSe-MSA nanocrystals under solar light irradiation. 
Figure 18

Apparent first order rate constant of MB degradation in the presence of CdSe-MSA nanocrystals under UV and solar light irradiations

Figure 19

Proposal of degradation mechanism of MB dye using CdSe-MSA nanocrystals under sunlight irradiation

\section{Supplementary Files}

This is a list of supplementary files associated with this preprint. Click to download.

- supplementaryfile.docx 